\title{
Something old, something new and something borrowed: emerging paradigm of insulin-like growth factor type 1 receptor (IGF-1R) signaling regulation
}

\author{
Leonard Girnita $\cdot$ Claire Worrall • \\ Shin-Ichiro Takahashi · Stefan Seregard • Ada Girnita
}

Received: 11 May 2013 / Revised: 17 October 2013 / Accepted: 7 November 2013 / Published online: 26 November 2013

(C) The Author(s) 2013. This article is published with open access at Springerlink.com

\begin{abstract}
The insulin-like growth factor type 1 receptor (IGF-1R) plays a key role in the development and progression of cancer; however, therapeutics targeting it have had disappointing results in the clinic. As a receptor tyrosine kinase (RTK), IGF-1R is traditionally described as an ON/ OFF system, with ligand stabilizing the ON state and exclusive kinase-dependent signaling activation. Newly added to the traditional model, ubiquitin-mediated receptor downregulation and degradation was originally described as a response to ligand/receptor interaction and thus inseparable from kinase signaling activation. Yet, the classical model has proven over-simplified and insufficient to explain experimental evidence accumulated over the last decade, including kinase-independent signaling, unbalanced signaling, or dissociation between signaling and receptor downregulation. Based on the recent findings that IGF-1R "borrows" components of G-protein coupled receptor (GPCR) signaling, including $\beta$-arrestins and $\mathrm{G}$-protein-related kinases, we discuss the emerging paradigm for the IGF-1R
\end{abstract}

L. Girnita $(\bowtie) \cdot$ C. Worrall · A. Girnita

Department of Oncology and Pathology, Cancer Center

Karolinska, CCK R8:04, Karolinska Institute, Karolinska

University Hospital, 17176 Stockholm, Sweden

e-mail: leonard.girnita@ki.se

\section{S.-I. Takahashi}

Departments of Animal Sciences and Applied Biological

Chemistry, Graduate School of Agriculture and Life Sciences,

The University of Tokyo, Tokyo, Japan

\section{S. Seregard}

Ophthalmic Pathology and Oncology Service, St Erik's Eye

Hospital and Karolinska Institute, Stockholm, Sweden

\section{A. Girnita}

Dermatology Department, Karolinska University Hospital, 171

76 Stockholm, Sweden as a functional RTK/GPCR hybrid, which integrates the kinase signaling with the IGF-1R canonical GPCR characteristics. The contradictions to the classical IGF-1R signaling concept as well as the design of anti-IGF-1R therapeutics treatment are considered in the light of this paradigm shift and we advocate recognition of IGF-1R as a valid target for cancer treatment.

Keywords IGF-1R · GRKs · IRS · Beta-arrestins · Serine phosphorylation · Cancer · Ubiquitination · GPCR · RTK

$\begin{array}{ll}\text { Abbreviations } \\ \text { aa } & \text { Amino acid residues } \\ \text { A-loop } & \text { Activation loop } \\ \text { ATP } & \text { Adenosine triphosphate } \\ \text { CH2 } & \text { Collagen homology 2 domain } \\ \text { C-terminal } & \text { Carboxyl terminal } \\ \text { cAMP } & \text { Cyclic adenosine monophosphate } \\ \text { CREB } & \text { cAMP response element binding-protein } \\ \text { ECM } & \text { Extra-cellular matrix } \\ \text { EGFR } & \text { Epidermal growth factor receptor } \\ \text { ERK } & \text { Extracellular-related kinase } \\ \text { ES } & \text { Ewing sarcoma } \\ \text { GDP } & \text { Guanosine diphosphate } \\ \text { GSK 3 } \beta & \text { Glycogen synthase kinase } \\ \text { GTP } & \text { Guanosine triphosphate } \\ \text { G proteins } & \text { Guanine nucleotide binding-proteins } \\ \text { GPCRs } & \text { G-protein coupled receptors } \\ \text { Grb2 } & \text { Growth factor receptor bound protein } \\ \text { GRKs } & \text { GPCR-related kinases } \\ \text { IGF } & \text { Insulin-like growth factor } \\ \text { IGFBP } & \text { Insulin-like growth factor binding-protein } \\ \text { IGF-1R } & \text { Insulin-like growth factor-type 1 receptor } \\ \text { IR } & \text { Insulin receptor } \\ \text { IRR } & \text { Insulin receptor-related receptor } \\ & \end{array}$




$\begin{array}{ll}\text { IRS } & \text { Insulin receptor substrate } \\ \text { MAPK } & \text { Mitogen-activated protein kinase } \\ \text { Mdm2 } & \text { Mouse double minute 2 homolog } \\ \text { MEK } & \text { Mitogen-activated protein kinase } \\ \text { N-terminal } & \text { Amino terminal } \\ \text { PDK } & \text { 3-Phosphoinositide-dependent protein kinase } \\ \text { PH } & \text { Pleckstrin homology } \\ \text { PTB } & \text { Phosphotyrosine binding domain } \\ \text { PI3K } & \text { Phosphoinositol 3 kinase } \\ \text { PIP3 } & \text { Phosphoinositol triphosphate } \\ \text { PPP } & \text { Picropodophyllin } \\ \text { RTKs } & \text { Receptor tyrosine kinases } \\ \text { TK } & \text { Tyrosine kinase } \\ \text { TKI } & \text { Tyrosine kinase inhibitor } \\ \text { SAPK } & \text { Stress-activated protein kinase } \\ \text { SH2/3 } & \text { Src homology } 2 / 3 \text { domain } \\ \text { Shc } & \text { SH2 domain-containing-protein } \\ \text { SOCS } & \text { Suppressor of cytokine signaling } \\ \text { Sos } & \text { Son of sevenless } \\ \text { SRF } & \text { Serum responsive factor } \\ \text { TKI } & \text { Tyrosine kinase inhibitor }\end{array}$

\section{Introduction}

Transmission of extracellular signals across the plasma membrane by receptors is a fundamental, evolutionary conserved cellular process. These signals are in part generated by specialized plasma membrane receptors, grouped into different families based on their specific structural characteristics. Although different receptor families utilize common intracellular signaling-proteins and activate common signaling pathways, each cell surface receptor family leads to specific biological outcomes in the cell [1].

The receptor tyrosine kinases (RTKs) represent one major cell surface receptor family, containing around 60 members, subdivided into at least 13 receptor families [2,3]. The RTKs are defined by the presence of an intracellular tyrosine kinase domain and typically a large glycosylated extracellular ligand binding domain, separated by a single transmembrane pass [4]. Traditionally defined by their ligands and hence ligand binding domains, the cytoplasmic kinase regions, juxtamembrane domain and carboxyl (C)-terminal tail also differ significantly among the individual receptors.

The canonical, binary model still in use today, describes the RTKs as having an OFF/ON mechanism. The agonist stabilizes the "ON" state through autophosphorylation of tyrosine residues within the kinase domain, followed by exponential increase in its kinase activity and subsequent activation of the intra-cellular signaling pathways [1]. In most cases, the ligand-induced activation of the kinase domain is mediated by receptor oligomerization (for reviews, see [4-6]). This event favors interactions between cytoplasmic kinase-partners and induces kinase transactivation. Dimerization can take place between two identical receptors (homodimerization), between different members of the same receptor family, or, in some cases, between a receptor and an accessory protein (heterodimerization) [69]. How ligands bind to receptors and induce oligomerization seems specific for each class of RTK [7, 10].

Over the last decades, RTKs have received particular attention, not only as essential regulators of normal cellular processes but also as key factors involved in the development and progression of human cancers. From the first discovery of a mutated RTK in cancer in 1984 [11], a huge amount of information about aberrant RTK signaling in cancer has built up, leading to incontestable recognition of various forms of RTK hyper-activation in cancer: gene amplification, overexpression, mutation, or autocrine growth factor loops that are responsible for the cancer-promoting potential of RTKs [12].

Among RTKs, the insulin-like growth factor type-1 receptor (IGF-1R) is one of the most important players in cancer development. The fundamental evidence for this is the demonstration that IGF-1R knock-out mouse embryonic cells are refractory to transformation by several oncogenes, viruses, or over-expression of other RTKs [13]. Subsequently, IGF$1 \mathrm{R}$ and its natural ligands were demonstrated to regulate multiple cellular functions essential for the malignant phenotype including cellular proliferation, survival, anchorageindependent growth, tumor neovascularization, migration, invasion, and metastasis [14-17]. Confirming this critical role, in preclinical settings, a large amount of experimental data clearly demonstrates that inhibition of IGF-1R would be beneficial for cancer treatment [18-24]. In vivo and in vitro studies using IGF-1R antibodies, small molecule inhibitors, and antisense technology have shown that IGF-1R is functionally essential for tumor cell growth and proliferation in most if not all forms of cancer [23, 25-28]. On the other hand, in clinical settings, no clear mechanism of aberrant IGF-1R could be recognized: IGF-1 or IGF-1R over-expression is not a general rule $[17,29]$, the receptor does not show intrinsic receptor abnormalities [30], and therefore other regulatory pathways and quantitative changes are likely to be involved and have to be considered.

This review will follow the development of our understanding of IGF-1R signaling and relate it to the models considered when different IGF-1R-targeting strategies are designed, in particular with regards to cancer therapy.

\section{Something old: classical signaling pathways through IGF-1R phosphorylation}

The IGF family includes ligands, receptors, and IGF-binding-proteins (IGFBPs). Classically, there are three ligands 
Fig. 1 IGF-1R structurefunction relationship. The map of the IGF-1R is annotated with the numbered aa residues. The key residues as determining binding of substrates/adaptor proteins are highlighted and linked with the binding partners. The known sites of posttranslational modifications (PTMs) within the $\beta$-subunit are indicated

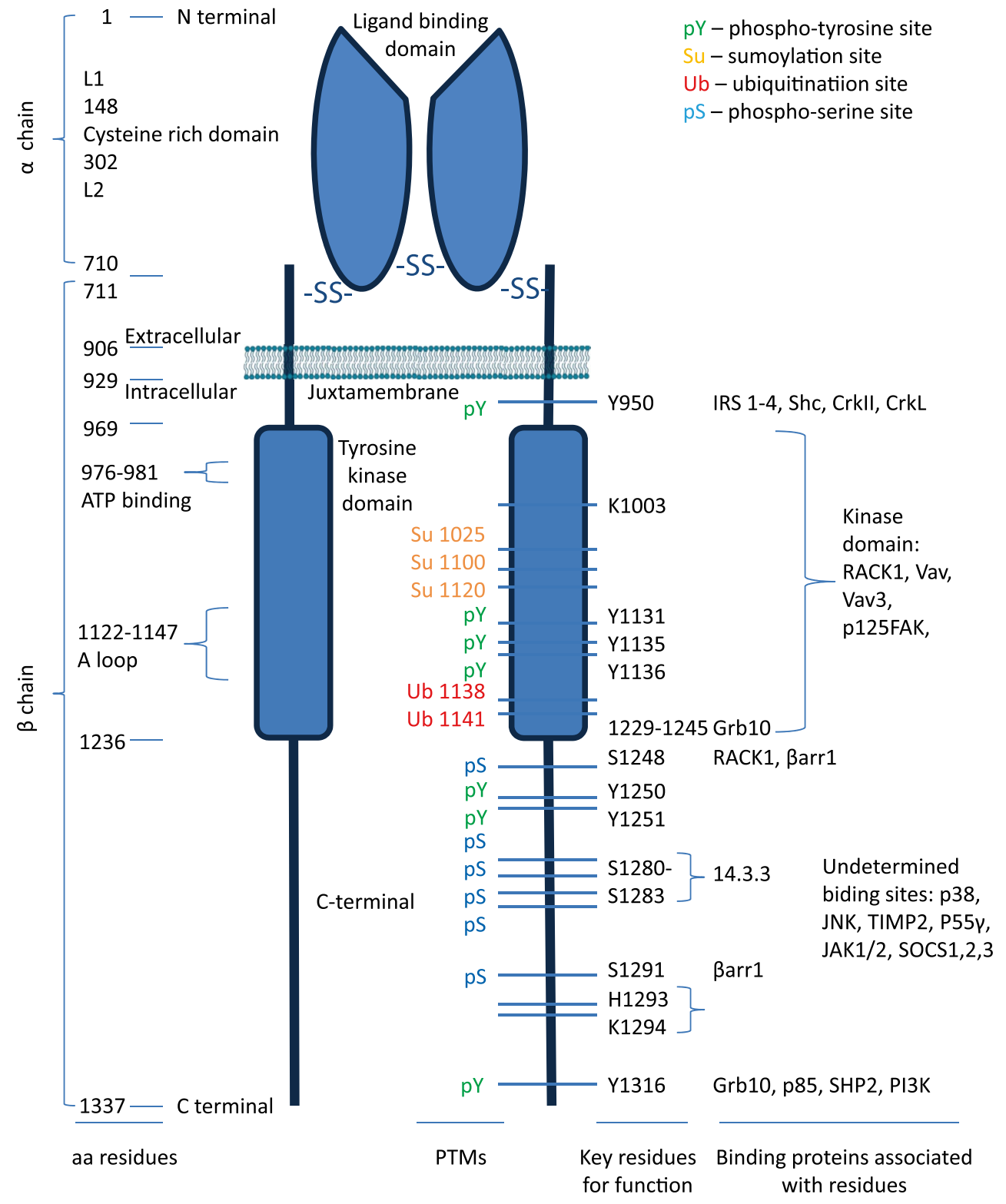

(insulin, IGF-1, and IGF-2), three cell surface receptors [insulin receptor (IR), IGF-1R, and IGF-2R] and at least seven IGFBPs modulating the biological activity of the growth factors [31-33].

Besides these archetypal members, more recent work has identified other proteins as potential members of the IGF family: the antimicrobial peptide LL-37 as ligand [34], the orphan insulin-receptor-related receptor (IRR) [35], the insulin-IGF-1R hybrid receptor [36, 37], and a growing number of IGFBPs [38].

Unlike other RTKs, the IR and IGF-1R exist as preformed dimers (Fig. 1). The IGF-1R has a membrane spanning tetrameric structure. It is synthesized as a single chain $\alpha-\beta$ pro-receptor which is processed by proteolysis and glycosylation [33, 39]. In mature, functional form, it consists of two identical extra cellular $\alpha$-subunits and two identical $\beta$-subunits, all linked by disulfide bridges. The $\beta$-chain contains an extra cellular domain, a transmembrane domain, and a kinase-containing intracellular domain [39, 40] (Fig. 1). On the whole, there is high homology (70 \%) between the IGF-1R and the IR amino acid sequences [40, 41].

The $\alpha$-subunit contains 710 amino acids (aa 1-710) and has in its structure two homologous domains (L1 and L2) separated by a cysteine-rich domain $(48 \%)$ containing 25 or 27 cysteines, in three repeating units [33]. The cysteine-rich domain (aa 148-302) is responsible for the ligand binding and is also conserved in the IR [42-46]. The spanning plasma membrane $\beta$-subunit contains 627 amino acid residues (aa 711-1337), distributed among the extra 
Table 1 IGF-1R structurefunction relationship
The key residues for posttranslational modifications, protein-protein interaction and their functional outcome as determined by mutationanalysis are summarized

$K$ kinase activity, $I$ internalisation, $M$ mitogenic, $T$ transforming, $A$ antiapoptotic, $M / I$ migration/ invasion, $S u$ Sumoylated residue, $U b$ ubiquitinated residue, $p Y$ phosphotyrosine, $p S$ phosphoserine

\begin{tabular}{|c|c|c|}
\hline Residues & Binding partners & Functions \\
\hline V922 & & M [267] \\
\hline Y943 & & I [50] \\
\hline Y950 & $\begin{array}{c}\text { IRS-1/2/3/4 [268-271], Shc }[268,269, \\
\text { 272], CrkII, CrkL [82, 273, 274] }\end{array}$ & I $[49,50], \mathrm{M}, \mathrm{T}[89,275-278], \mathrm{pY}$ \\
\hline Y957 & & I [50] \\
\hline Kinase domain 969-1236 & $\begin{array}{l}\text { RACK1 [87], Vav [80], Vav3 [81], } \\
\text { p125FAK [83] }\end{array}$ & \\
\hline $976-981$ & & ATP binding site, A [89] \\
\hline K1003 & & A, M, T, K [89, 279] \\
\hline $\mathrm{K} 1025, \mathrm{~K} 1100, \mathrm{~K} 1120$ & & $\mathrm{Su}[151]$ \\
\hline K1081 & & [280] \\
\hline G1125 & & $\mathrm{K}$ [281] \\
\hline K1138, K1141 & & $\mathrm{Ub}[141]$ \\
\hline Y1131, Y1135, Y1136 & & $\begin{array}{l}\text { Auto-phosphorylation, M, T, K [89, } \\
\text { 234, 276, 282, 283], pY }\end{array}$ \\
\hline W1173 & & A, T [284] \\
\hline Y1221 & & K [276] \\
\hline $1229-1245$ & Grb10 [78] & \\
\hline S1248 & RACK1 [88], $\beta \operatorname{arr} 1[124,134]$ & $\mathrm{pS}$ \\
\hline Y1250 & & T [128], M/I, A [89, 276, 285] \\
\hline Y1251 & & I [286], K [276], A, T [89] \\
\hline S1252 & & pS, I [280] \\
\hline S1272 & $14.3 .3[287]$ & \\
\hline S1280-S1283 & 14.3.3 [268, 288, 289] & T $[290,291]$ \\
\hline S1291 & $\beta$ arr1 $[124,134]$ & $\mathrm{pS}$ \\
\hline H1293-K1294 & & A $[89,292]$ \\
\hline F1310 & & A [277] \\
\hline Y1316 & $\begin{array}{l}\text { Grb10 [79], p85 [293], SHP2 [84, } \\
\text { 145], PI3K [63] }\end{array}$ & {$[89,292]$} \\
\hline Undetermined & 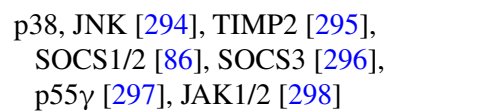 & \\
\hline
\end{tabular}

cellular domain (196 aa), the transmembrane domain (aa 906-929), and the intracellular portion of the $\beta$-subunit, which itself is subdivided into three domains: a juxtamembrane domain, the tyrosine kinase (TK) domain, and C-terminal domain/tail. The juxtamembrane domain contains an NPXY motif, which may be important for receptor internalization [47-50]. The catalytic region of IGF-1R contains the ATP binding motif (GXGXXG) at positions 976-981, and a catalytic lysine in position 1003 , which is critical for the Mg-ATP binding [51]. Within the TK domain, a cluster of three tyrosines, located at positions 1131, 1135, and 1136 , is critical for receptor autophosphorylation [41]. The C-terminus of the IGF-1R (roughly the last 100 amino acids) contains several regulatory elements essential for IGF-1R function [52] (Table 1; Fig. 1).

The TK domain is highly homologous to that of the IR $(84 \%)$, the juxtamembrane domain shares $61 \%$ of homology with the IR, whereas the C-terminal domain shares only $44 \%$ [40]. Despite this high degree of homology, it is largely accepted that the two receptors have distinct biological roles. The IR is known to be a key regulator of physiological processes such as glucose transport and biosynthesis of glycogen and fat [53], whereas the IGF-1R is a potent regulator of cell growth, proliferation, and differentiation $[54,55]$. The structure-function relationship of the IGF-1R has been extensively investigated, with mutational analysis revealing residues crucial for the binding of signaling or adaptor proteins (Table 1; Fig. 1) or particular downstream bioactivities (Table 1).

IGF-1R tyrosine kinase activation

According to the classical model, IGF-1/2 binding induces a conformational change in the preformed dimeric receptor, leading to activation of the RTK [6]. In the unphosphorylated state, the receptor catalytic activity is very low 


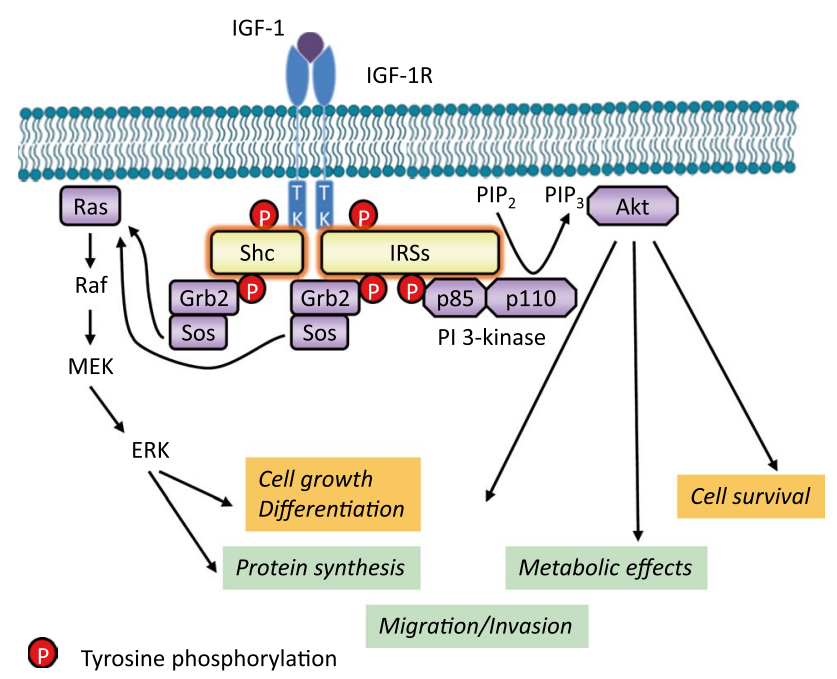

Fig. 2 IGF-1R kinase-dependent signaling pathways. IGF-1 (or IGF2) binding to the IGF-1R promotes intrinsic tyrosine kinase activity and auto-phosphorylation. Activated receptor can recruit and phosphorylate substrates such as IRS and Shc. Tyrosine phosphorylation of IRS and Shc proteins leads to binding of signaling molecules such as Grb2 and PI 3-kinase. These associations induce downstream signaling activation, primarily through the MAPK and PI3K pathways coordinating downstream IGFs bioactivities

due to the inhibitory conformation of a specific domain in the kinase region, which interferes with ATP-binding and tyrosine phosphorylation. This domain, known as the activation loop (A-loop), behaves as a pseudosubstrate that blocks the active site [56]. The A-loop contains the critical tyrosine (Tyr) residues 1131, 1135, and 1136 and the activation of intrinsic protein kinase activity results in the autophosphorylation of them [56] (Fig. 1). Tyr 1135 (being the first tyrosine to be phosphorylated) in the A-loop is bound in cis position in the active site, thus preventing substrate access while simultaneously occluding the ATP binding site. The kinase activity is at a low basal level, but sufficient to induce trans-autophosphorylation, once stimulated. After ligand binding, the three tyrosines of the A-loop are trans-phosphorylated by the dimeric subunit partner. Phosphorylation of Tyr 1135 and Tyr 1131 destabilizes the auto-inhibitory conformation of the A-loop, whereas phosphorylation of Tyr 1136 and, to a lesser extent, Tyr 1135 stabilizes the catalytically optimized conformation of it [56]. Autophosphorylation of Tyr 1135 is necessary but not sufficient to destabilize the autoinhibitory A-loop conformation; full destabilization also requires autophosphorylation of Tyr 1131. Autophosphorylation also occurs outside the kinase domain and creates docking sites for downstream signal transduction molecules. According to the classical model, the two main downstream signaling pathways activated by IGF-1R kinase are the MAPK and PI3K pathways (Fig. 2).
Intracellular substrates of the IGF-1R tyrosine kinase

The docking sites outside the kinase domain bind signal transduction molecules and adaptor proteins to activate downstream signaling pathways. One important docking site of the IGF-1R to a substrate is the NPXY950 motif in the juxtamembrane domain. This motif is recognized by the phosphotyrosine binding (PTB) domain that the insulin receptor substrates (IRSs) and the src homology 2 (SH2)-containing-protein (Shc) possess (Figs. 1, 2). Extensive mutation analysis exposed the specific residues involved in binding these substrates as indicated in Fig. 1 and Table 1.

After phosphorylation of the tyrosine residues of the $\beta$-subunit of the IGF-1R, the first molecule that reaches full binding in 1-2 min is the IRSs. The IRS protein family consists of four proteins from IRS1 to IRS4. Among them, IRS1 and IRS2 are well known to play important roles in mediating metabolic effects of the IGFs as well as their cell growth and differentiation activities. Each IRS possesses high homology regions: a pleckstrin homology domain $(\mathrm{PH})$ and a PTB domain at the $\mathrm{N}$-terminal region. These regions are thought to be important for interaction with cell surface receptors. The C-terminal region of IRS proteins is poorly conserved, suggesting that this region mediates the different biological activities of each IRS. It also has a C-terminal domain with multiple potential phosphorylation sites (more than 20 in IRS1/2/4) that interact with high affinity to $\mathrm{SH} 2$ domain-containingproteins in a manner dependent on the specific phosphotyrosine motif (YXXX) involved [57]. The SH2 domaincontaining-proteins include a p85 regulatory subunit of phosphatidylinositol 3-kinase (PI3K) class I, growth-factor-receptor-bound protein 2 (Grb2), SH-PTP2 (a tyrosine phosphatase), and other adaptor proteins like Crk and Nck. IRS1, as a docking-protein, has been involved in interactions with multiple molecules secondary to IGF$1 \mathrm{R}$ activation, and among them $\beta 1$ integrins seem to have an important role in cell adhesion to laminin after IGF-1 stimulation [58]. In addition, a recent study described that IRSs form high-molecular-mass complexes with a variety of proteins in a phospho-tyrosine-independent manner and modulate their availability to the IGF-1R $[59,60]$.

The second major pathway is through Shc, which reaches its maximal phosphorylation within 5-10 min of IGF-1R stimulation. Shc has been shown to consist of four unique members, ShcA, B, C, and D, and multiple splicing isoforms [61]. In general, Shc proteins possess a PTB domain at the $\mathrm{N}$-terminal region and a $\mathrm{SH} 2$ domain at the C-terminal region. Between the PTB domain and SH2 domain, there are three tyrosine residues, possibly phosphorylated by IGF-1R, involved in Grb2 recruitment. 


\section{PI 3-kinase pathway}

One of the downstream pathways activated by the IGF-1R involves IRS interaction with a p85 regulatory subunit of PI3K class I, leading to activation of the catalytic subunit p110 of PI3K and inducing phospholipid products activating the downstream signaling pathway [62].

It has also been shown that tyrosine phosphorylation of the IGF-1R (Y1316XXM) can also induce direct binding of PI3K to the cytoplasmic region of the receptor [63] (Figs. 1, 2).

One of the main functions of PI3K is to synthesize the second messenger phosphatidyl inositol $(3,4,5)$ triphosphate (PIP3) at the inner side of the membrane. These phospholipids function as ligands for recruiting $\mathrm{PH}$ domain-containing-proteins to the inner surface of the cell membrane [39]. The Akt/PKB serine threonine kinase interacts with these phospholipids causing its translocation to the inner membrane and activation by the 3-phosphoinositide-dependent protein kinases (PDKs) located around the membrane. IGFs-mediated activation of the PI3K pathway induces phosphorylation of the Thr308 and Ser473 residues on Akt and activates this kinase [64, 65]. Active Akt in turn phosphorylates and inhibits several pro-apoptotic proteins such as Bad [66] and caspase 9 [67], plus at least three other Akt effectors: the survival transcription factor cyclic AMP response element binding-protein (CREB), the pro-apoptotic effector protein glycogen synthase kinase-3 $\beta$ (GSK-3 $\beta$ ), and the winged-helix family of forkhead transcription factors FKHRL1, FKHR, and AFX. Akt activation can also induce stimulation of mTOR that will lead to phosphorylation of the 40S ribosomal S6 protein by the p70S6 kinase, thereby enabling efficient translation of $5^{\prime}$ terminal oligopyrimidine tract (5'TOP) mRNA [68]. This class of mRNA is critically involved in the control of the protein synthesis machinery regulating the transition from G0 to G1 of the cell cycle. Activated mTOR can also induce phosphorylation of eukaryotic initiation factor $4 \mathrm{E}$ (eIF-4E) binding-protein (4E-BP), thus regulating cell cycle proteins like cyclin D1 [69]. mTOR is also involved in activation of matrix metallo proteinase (MMP) 2 with effects on cell migration and metastasis potential [70]. Another effect of Akt activation is phosphorylation of Mdm2 on serine 166 and serine 186. Phosphorylation on these sites is necessary for translocation of Mdm2 from the cytoplasm into the nucleus, where Mdm2 decreases p53 transcriptional activity and hence diminishes cellular levels of p53 [71].

\section{MAP kinase pathway}

The second major pathway is mediated by tyrosine-phosphorylated IRSs or Shc through another
SH2-domain-containing signaling molecule, Grb2 (Figs. 1, 2). Grb2 is an adapter protein which possesses one SH2 and two SH3 domains. Grb2 can be activated by binding directly to phosphorylated IRS or She via its SH2 domain, while the SH3 domains interact with son of sevenless (Sos), a guanine nucleotide exchange protein. Sos stimulates the release of GDP and subsequent binding of GTP to the membrane-bound, low-molecular-mass GTP-binding-protein Ras. GTP-bound Ras interacts with and translocates the serine/threonine protein kinase Raf to the plasma membrane, where Raf becomes activated. Activated Raf phosphorylates and activates the dual specificity mitogen-activated protein kinase (MAPK) MEK, which in turn stimulates the ERK subset of MAPKs: extracellular-related kinase (ERK) 1 and ERK2. ERK1/2 are translocated into the nucleus where they are involved in spindle formation. ERK also mediates transcriptional induction of the cyclin D1 gene, stimulating phosphorylation of the $\mathrm{pRb}$ protein and release of the E2F-1 transcription factor [72]. The free E2F-1 can activate in its turn the transcription of $\mathrm{p} 14^{\mathrm{ARF}}$ [73]. ARF was shown to inhibit the p53-Mdm2 association that maintains p53 in its inactive form [74]. In its turn, p53 can directly interfere with the Ras/MAPK cascade by inactivating ERK2/MAPK via caspase-mediated cleavage [75]. One of the other substrates of MAPK is p90Rsk. Both MAPK and p90Rsk translocate to the nucleus after phosphorylation, where they phosphorylate and activate transcription factors such as serum-responsive factor ( $\mathrm{SRF}$ ), $\mathrm{T}$ cell-specific transcription factor, and CREB, and, thus, alter gene expression. In the cytoplasm, MAPK regulates microtubule dynamics by phosphorylating microtubule-associated proteins. By regulating microtubule networks, MAPK regulates the CyclinB/Cdc2 complex: Cyclin B phosphorylation by MAPK is important for the translocation of the complex to the nucleus where it is activated by CDC $25 \mathrm{C}$ $[76,77]$.

Other downstream signaling pathways

Previous studies to identify potential substrates of the IGF$1 \mathrm{R}$ and/or interactions with the receptor after its activation have revealed several additional possible downstream signaling molecules. One of these, Grb10, is a member of a super family of adaptor proteins, sharing a common overall structure, including an $\mathrm{N}$-terminal region harboring a conserved proline-rich motif, a central $\mathrm{PH}$ domain, and a C-terminal SH2 domain. Ligand activation of the IGF-1R involves the Grb10 adaptor protein, which probably binds to autophosphorylated tyrosine residues located between amino acids 1229 and 1245 of IGF-1R [78] or tyrosine 1316 [79]. Activated Grb10 interacts with neuronal precursor cell-expressed developmentally downregulated 4 
(Nedd4), and by doing this it has an important role in ubiquitination of the IGF-1R. Other substrates of the IGF-1R tyrosine kinase include the guanine nucleotide exchange factors Vav [80] and Vav3 [81], the adapters CrkII and CrkL [82], and focal adhesion kinase (FAK) [83]. Aside from IRS proteins, IGF-1R has been reported to interact in vitro and/or in vivo with numerous molecules, including Syp [39], GTPase-activating-protein [84], C-terminal Src kinase [85], and suppressor of cytokine signaling (SOCS)2 [86]. The IGF-1R can also activate the stress-activated protein kinases (SAPKs) including p38 and Jun $\mathrm{N}$ terminal kinase (JNK), a pathway associated with regulation of DNA damage responses and cell survival. It has been shown that RACK1, a small molecule that was identified as an IGF$1 \mathrm{R}$ interacting protein using a yeast two-hybrid interaction trap, regulates IGF-1R signaling and interaction of the IGF1R with integrin signaling [87-89]. However, information regarding the roles of many of these molecules in IGF-1R signaling and biological functions is currently limited.

The classical IGF-1R signaling cascades are more complex, and they have been described in great detail in some dedicated reviews [1, 23, 33, 37, 41, 90-94].

\section{Something new: posttranslational modification of IGF-1R controlling IGF-1R expression and function}

\section{Receptor internalization and signal attenuation}

Owing to the presence of an intracellular tyrosine kinase domain, IGF-1R is classified as an RTK, and accordingly phosphorylation was considered to be the central process governing IGF-1R signaling [94, 95]. However, during the last decade, several laboratories have been investigating the mechanisms controlling the subsequent receptor downregulation and signaling desensitization. In this context, other posttranslational modifications including dephosphorylation, serine phosphorylation, ubiquitination, and sumoylation are increasingly recognized as modulating receptor levels and function.

Many cell surface receptors undergo endocytosis, being incorporated into clathrin- [96] or caveolin-coated vesicles. Some receptors are internalized constitutively and recycled (e.g., the transferrin receptor); however, with most RTKs and G-protein-coupled receptors (GPCRs), internalization is triggered by ligand binding [97, 98]. Ligand-activated receptors are normally downregulated by internalization [99-101], allowing the cells to return to an unstimulated, basal state. This internalization is considered to occur only for phosphorylated receptors [99-101], and is thus ligand-dependent.

Clathrin- or caveolin-mediated internalization then follows a process through early endosomes to late endosomes, during which decisions regarding fate of the proteins are made: whether to recycle or degrade. Early endosomes are mildly acidic, allowing detachment of the ligand and hence attenuation of the signal $[102,103]$. If the receptor is to be degraded, it will progress to the highly acidic, hydrolasecontaining lysosomal compartments. Internalization of a receptor does not necessarily mean immediate cessation of the signal followed by receptor degradation. This ligandmediated endocytosis appears to have a double function: although subsequently attenuating the signal from activated receptors, it is also facilitating the interaction between the internalized receptor and the downstream signaling molecules [103]. For example, signaling through the EGFR is maintained in endosomal compartments and determines the longevity of the signaling [104, 105].

The ubiquitin pathway is a regulatory system for endocytosis [99-101, 106], and RTKs are well recognized as targets of ubiquitination [107]. Ubiquitination is the covalent attachment of the 7-kDa ubiquitin polypeptide to lysine residues on target proteins through the sequential actions of E1, E2, and E3 ligase enzymes [108, 109]. E1 and E2 work to load the E3 ligase with the ubiquitin, while E3 transfers the ubiquitin to the target protein. The E3 provides the specificity for the substrate, binding directly or through adaptor proteins. Ubiquitination can either be mono- (single ubiquitin moiety) or poly- (where chains of ubiquitin are added). Proteins can be multi-ubiquitinated (at multiple lysine residues) and polyubiquitination can be straight or branched type, depending on which of the lysine residues within ubiquitin the subsequent ubiquitin is attached [101, 110-112]. The type of ubiquitination is increasingly being recognized as determining the fate of the substrate protein [113]. Old or damaged cytosolic proteins are labeled with a polyubiquitin chain, which is recognized by the proteasome, multi-subunit proteolytic enzymes situated in the cytoplasm.

In addition to the degradation of cytosolic proteins, ubiquitin is also implicated in the internalization and degradation of plasma membrane proteins. In mammalian cells, a number of membrane proteins which are ubiquitinated are degraded through both the proteasome and lysosomal pathways [100], including the IGF-1R [114-117] and other RTKs [118, 119]. In some cases (e.g., the RTK Met), cytoplasmic fragments are cleaved from the receptor and degraded by the proteasome, in a complementary mechanism to lysosomal degradation [119].

IGF-1R internalization, recycling, and degradation

The IGF-1R has been shown to be ubiquitinated [116, 117, 120] and internalized, through both clathrin and caveolin routes, in a ligand-dependent manner [116, 117, 120, 121]. Ubiquitination of the IGF-1R occurs prior to entry into 
endocytotic vesicles [120]. IGF-1R internalization reaches an apparent plateau after $20 \mathrm{~min}$ at $37{ }^{\circ} \mathrm{C}$ in cultured hippocampal neurons, while half-maximal IGF-1R internalization was obtained after $5 \mathrm{~min}$ at $37{ }^{\circ} \mathrm{C}$ in NIH-3T3 fibroblasts [122]. After internalization, some receptors are sorted for recycling to the cell surface. In activated T lymphocytes, internalization of the IGF-1R from the cell membrane was accompanied by a reduction in its mRNA. This was followed by re-expression of IGF-1R on the cell surface and an increase in IGF-1R mRNA levels in the cytoplasm, reaching levels higher than those initially recorded. However, a slower increase in the mRNA levels indicated that the earlier recovery of IGF-1R results from receptor recycling, followed by de novo synthesis [123]. There are certainly internal routes where the IGF-1R is recycled back to the cell surface and where this balance between recycling and degradation can be manipulated [124]. After internalization, IGF-1R degradation is mediated by both the proteasome and lysosomal pathways or recycled to the plasma membrane $[100,114,116,117,120]$, although the relative roles of each are not clear.

A key question is: what is the downregulation signal for IGF-1R? To answer this question, at least two models have emerged during the last decade: one postulating internalization by a tyrosine-based motif and another by an ubiquitin-based motif. However, these two are not mutually exclusive, with phospho-tyrosine motifs potentially modulating ubiquitination and hence mediating receptor internalization.

Tyrosine motif-based downregulation model

The ligand-activated receptors are targeted to clathrincoated membrane invaginations [125], a process mediated by a specific internalization signal situated within cytoplasmic domain of the receptor [100]. There is evidence that internalization signals have a tyrosine-based motif usually located within the juxtamembrane region of the receptor [126, 127]. The human IGF-1R contains three tyrosine residues in the juxtamembrane region [50] that may be involved in internalization. However, contradictory results have been reported regarding the role of these tyrosinebased motifs as internalization signals. Prager et al. [50] demonstrated that the NPXY motif in IGF-1R is important for receptor internalization, whereas Miura et al. [128] demonstrated that tyrosine 1250 within the IGF-1R tail is the functional tyrosine-based internalization signal (Fig. 1).

\section{Ubiquitin motif-based downregulation model}

Degradation of the IGF-1R by a proteasome mediated route was originally described by Sepp-Lorenzino et al. [114] to explain the mechanism of Herbymicin A-induced IGF-1R downregulation. Herbymicin A was demonstrated to only degrade IGF-1R in the presence of functional ubiquitin E1 ligase activity, and its action was prevented by proteasome inhibitors while being insensitive to lysosomal inhibitors. Since then, the IGF-1R has been demonstrated to be a substrate of three E3 ubiquitin ligases: Mdm2 [116], Nedd4 [120], and c-Cbl [117].

After Grb10 recognition as an IGF-1R interacting partner and negative regulator of IGF-1 signaling [78, 129], a yeast two-hybrid screen subsequently identified Grb10 as a binding partner of the Nedd4 E3 ligase [130]. Grb10 overexpression increased ligand-dependent IGF-1R ubiquitination, receptor internalization, and degradation. This ubiquitination did not occur with a catalytically inactive Nedd4 or with mutant Grb10 unable to bind Nedd4 [120]. This work identified Nedd4 as an ubiquitin E3 ligase and Grb10 as the key adaptor protein to recruit Nedd4 to the IGF-1R. Further work from the Morrione laboratory described Nedd4 ubiquitination of the IGF-1R as predominantly of multimonoubiquitination type [131]. In addition, the internalization mediated by Nedd4 was both clathrin- and caveolin-dependent as demonstrated by co-localization studies [131].

Following original research demonstrating a feedback mechanism of wild-type p53 negatively regulating IGF-1R at the transcriptional level [132], it was revealed that overexpressed mutant or wild-type p53 mitigate ligand-induced IGF-1R downregulation [29]. Analysis of IGF-1R mRNA levels discard an exclusively transcriptional mechanism, indicating a posttranslational p53-IGF-1R control mechanism [29]. Further work demonstrated that an inhibition of p53 caused ubiquitination and degradation of the IGF$1 \mathrm{R}$, suggesting that $\mathrm{p} 53$ and IGF-1R might compete for the same ubiquitin ligase [116]. This possibility was validated in experiments in which inhibition of Mdm2 (the well-known p53 ubiquitin ligase) resulted in accumulation of IGF-1R [116]. This work confirmed the direct IGF1R/Mdm2 interaction, identified $\mathrm{Mdm} 2$ as an ubiquitin ligase for the IGF-1R, promoting proteasome-inhibitorsensitive IGF-1R degradation, and highlighted a positive posttranslational control mechanism between p53 and IGF-1R [116]. Subsequent research revealed the mechanism of Mdm2 binding to the IGF-1R by identifying that $\beta$-arrestins, otherwise known as master regulators of GPCR biology, serve as adaptors to bring the $\mathrm{E} 3$ ligase $\mathrm{Mdm} 2$ to the IGF-1R [133]. Both Mdm2 and $\beta$-arrestin co-immunoprecipitated with the IGF-1R and in an in vitro reaction $\beta$-arrestins enhanced Mdm2-mediated IGF-1R ubiquitination [133]. In a cell system, overexpression or depletion of $\beta$-arrestin 1 enhanced and decreased IGF-1R ubiquitination and degradation, respectively. Thus, $\beta$-arrestin 1 was proved to act as an essential component in the ubiquitination and downregulation of the IGF-1R [133]. Most 
recently, $\beta$-arrestin 1 was recognized not only as an aid to IGF-1R internalization and signal cessation but to initiate its own second wave of signaling through the MAPK/ ERK pathway [134], with IGF-1R stimulation also leading to ubiquitination of $\beta$ arrestin 1 [134]. Intriguingly, this $\beta$-arrestin 1-mediated ERK activation occurs even when the classical IGF-1R kinase signaling is impaired (see below) [134]. Taken together, these studies demonstrated that $\beta$-arrestin 1 serves as an adaptor to bring the E3 ubiquitinligase Mdm2 to the IGF-1R, with a dual outcome on the IGF-1R: ubiquitination and receptor downregulation as well as IGF-1R/ $\beta$-arrestin 1-mediated activation of MAPK signaling.

The identification of $\mathrm{c}-\mathrm{Cbl}$ as an ubiquitin-ligase for IGF-1R [117] was based on the observation that suppression of Mdm2 did not completely abolish ligand-induced IGF-1R ubiquitination, suggesting that there are other ligases contributing to this process. Previously recognized as an E3 ligase of other RTKs, including EGFR and PDGFR [135], c-Cbl was demonstrated to associate with and to ubiquitinate the IGF-1R [117], especially at higher doses of IGF-1, indicating complementary roles for the different E3 ligases [117]. In vitro experiments using ubiquitin with mutated lysine residues suggested that Mdm2 polyubiquitinates IGF-1R with K63 type chains, whereas c-Cbl polyubiquitinates IGF-1R with K48 type chains. Co-localization between caveolin and an early endosome marker showed that higher doses of IGF-1 increased caveolin-mediated endocytosis, whereas low doses did not. In agreement with IGF-1 concentration determining ligase and endocytotic processes, overexpression of Mdm2 could reduce caveolin-mediated endocytosis.

The E3 ligases Mdm2 and Nedd4 have been demonstrated to bind to the IGF-1R through the adaptor proteins $\beta$-arrestin 1 [133] and Grb10 [131], respectively, suggesting that adaptor proteins determine substrate specificity. For Nedd4, there is evidence of the ligase determining appropriate localization of the receptor [136], and that it directs towards a proteasome-independent pathway of degradation [137]. The ligases c-Cbl and Mdm2 appear to have complementary roles, with $\mathrm{c}-\mathrm{Cbl}$ recruited following high dose IGF-1 and initiating caveolin-dependent endocytosis and Mdm2 recruited at low dose IGF-1 and initiating clathrin-dependent endocytosis [117]. It is clear, however, that different ligases associated with the IGF-1R as well as their adaptor proteins have redundant as well as complementary roles: they keep the balance between recycling, relocalization, and proteasome/lysosomal degradation of the receptor $[117,120,121,131,133,134]$. The complexity is further increased by the fact that receptor signaling relies on its localization: signaling still occurs from endosomes and prevention of endocytosis is even inhibitory to signaling [84, 124, 134, 138].
Through IGF-1R mutation analysis, the interplay between phosphorylation and ubiquitination has been demonstrated [121]. According to this study, a completely kinase-dead IGF-1R (with mutation of the ATP pocket) cannot be ubiquitinated after ligand stimulation, while a kinase impaired IGF-1R (Y1136A) is ubiquitinated, activates ERK signaling, but fails to phosphorylate Akt. Deletion of the C-terminal tail $(\Delta 1245)$ had no effect on IGF-1R phosphorylation but completely abolished its ubiquitination [121], confirming the previous findings that IGF-1R ubiquitination is essentially dependent on its $\beta$-arrestin binding domain [133, 134].

Although initially described as a modification initiated by the natural ligand binding to the receptor, recent studies suggest that IGF-1R ubiquitination is a more complex process that can also be activated kinase-dependent (activationloop phosphorylation) by IGF-2 [139], insulin [139], LL-37 [140], or kinase-independent by anti-IGF-1R antibodies [140-142]. In addition, IGF-1R ubiquitination can be activated in a ligand and kinase-independent manner, from inside the cell, by adaptor proteins recruited to the intracellular domain of the IGF-1R [124, 143, 144]. The mechanism of IGF-1R ubiquitination is different depending on the ligand, adaptor protein, or ubiquitin-ligase employed; however, the common theme is that a specific receptor conformation may trigger ubiquitination with divergent effects on receptor signaling, trafficking, and biological outcomes. It should be noted here that such conformation-activating ubiquitination is not essentially dependent on ligand-receptor interaction or activation-loop phosphorylation.

\section{IGF-1R dephosphorylation}

Direct IGF-1R dephosphorylation has been little investigated. Rocchi et al. [145] described the association of activated IGF-1R with the phosphatase SHP2, with binding between phospho-tyrosines on IGF-1R and SH2 domains in SHP2 being critical. Subsequently, it was demonstrated that SHPS2 is critical for recruitment of SHP2 to the plasma membrane for this purpose [146]. Cross-talk with the $\alpha \mathrm{V} \beta 3$ integrin, through SHP2, was later described, with blockage of this integrin reducing IGF-1-induced IGF-1R phosphorylation [146, 147]. The phosphatase PTP1B also negatively regulates the IGF-1R [148], associating with it in a ligand-dependent manner [149].

\section{Nuclear IGF-1R}

Recently, there has been greater appreciation of plasma membrane receptor relocalization to the nucleus. Nuclear localization has been demonstrated for the IGF-1R and shown to be mediated by sumoylation, the addition of a small protein similar to ubiquitin $[150,151]$. The direction 
to the nuclear compartment and the role of nuclear IGF-1R is currently little investigated, but studies suggesting that IGF-1R nuclear localization can alter transcription [152], and that nuclear localization of IGF-1R predicts better outcome in patients treated with IGF-1R antibody [153], suggest that further research would have therapeutic relevance. One study has demonstrated that transfer to the nucleus is mediated at least in part by clathrin, and confirmed that both the $\alpha$ - and $\beta$-chains of IGF-1R translocate to the nucleus [154], suggesting a more complex function to IGF$1 \mathrm{R}$ internalization than solely degradation versus recycling. The emerging role of nuclear IGF-1R has recently been thoroughly reviewed by Sarfstein and Werner [155].

\section{Something borrowed: IGF-1R transactivation by other plasma-membrane receptors}

It is generally accepted that several posttranslational modifications control the IGF-1R levels at the cell surface, with direct impact on receptor signaling. Are these modifications, in combination with the "two-states" model, sufficient to explain the differential signaling efficacy of the IGF-1R? Described by terms such as "cross-talk" or "transactivation", it is increasingly recognised that IGF-1R signaling and efficacy is modified by interactions with other plasma-membrane molecules. This group include other RTKs, integrins, and GPCRs. Among the RTKs, probably the best studied is the IGF-1R interaction with the IR, resulting in formation of hybrid receptors $[187,188]$ which are able to respond to insulin, IGF-1, and IGF-2 but with different affinities. The mechanism of hybrid receptor activation, signaling, as well as their biological effects, have been extensively investigated [37, 139, 156-158]; however, it should be highlighted here that simple interaction of the IGF-1R with IR modified IGF-1R signaling and trafficking to various ligands [139] and anti-IGF-1R antibodies [156]. The IR is not the only RTK associated with the IGF-1R; for example, a direct interaction between the IGF-1R and EGFR was identified in cancer cells, with EGFR depletion affecting IGF-1R ubiquitination, degradation, and signaling [159]. In a similar manner, another group of plasma-membrane molecules were demonstrated to modify the IGF-1R response to IGF-1. Integrins, as transmembrane receptors, transfer information from the extracellular matrix (ECM) to signaling pathways inside cells (outside-in signaling) or from within the cell (inside-out signaling) [160]. They form part of cell surface signaling complexes known as focal adhesions which link the cytoskeleton to the ECM and are intimately linked with cell adhesion and migration [160]. There has been increasing recognition of the bi-directional cross-talk between integrins and the IGF-1R signaling pathway [161]: integrin activation modulating the
IGF-1R signaling and vice versa. Studies identifying the overlap between IGF-1R and integrin signaling pathways from the Clemmons group demonstrated IGF-1R-dependent "transactivation" of $\alpha v \beta 3$ integrin [162]. The mechanism was described as due to the recruitment and phosphorylation/dephosphorylation of adaptor proteins. IGF-1 stimulation causes phosphorylation of the transmembrane adaptor protein SHPS1 and subsequent SHP2 recruitment [146]. Along with SHP2, IGF-1R through IRS1 recruits the focal contact adaptor protein paxillin and FAK, which are involved in the turnover of focal contacts. IGF-1 stimulation leads to SHP2 dephosphorylation of paxillin and FAK, as part of an integrin deactivation mechanism crucial for migration [163]. In further evidence, the DOK1 protein, itself an IRS protein, brings SHP2 to the $\alpha \mathrm{v} \beta 5$ integrin [164]. IGF-1 is well known to initiate cell migration, IGF-1 triggers integrin activation and binding to ECM [165], and evidence showed that $\alpha v \beta 3$ and $\alpha v \beta 5$ are involved in the migratory/invasive IGF-1 response [165, 166].

However, there is also increasing recognition that the activation state of integrins alters IGF-1R signaling. The SHP2 protein is not only recruited to integrins and dephosphorylates paxillin and FAK but regulates IGF-1R dephosphorylation, curtailing the IGF-1R signaling response [146], identifying it as a common molecule between the integrin and IGF-1R signaling pathways. The Clemmons group also describe integrin modulation of the SHPS1IGF-1R association, with activation and tyrosine phosphorylation of $\alpha v \beta 3$ integrin determining the recruitment to the IGF-1R of SHPS1 and subsequently SHP2, and involving IAP [167, 168]. Overall, ligand occupancy of at least some integrins is required for a sustained IGF-1 response [169], and transmembrane integrin complexes including SHPS1 and IAP modulate IGF-1R signaling through determining SHP2 recruitment (reviewed in [170]), with subsequent effects on cell behavior [171].

The O'Connor group described a further common node between integrins and IGF-1R. The RACK1 scaffoldingprotein, known to interact with $\beta 1$ integrin, was identified as also binding IGF-1R affecting Shc/Grb2 downstream signaling [87, 172]. Further, the O'Conner group demonstrated that RACK1 associated mutually exclusively with phosphatase PP2A or $\beta 1$ integrin, controlled by IGF-1 stimulation [173]. However, this complex differed between transformed and non-transformed cells, with only transformed cells showing direct RACK1-IGF-1R interaction [174].

Recent work by the Takada group posited an extracellular determinant of cross-talk between the two pathways, in agreement with the co-localization of IGF-1R and integrins together at focal adhesion complexes. They demonstrated direct binding of IGF-1 ligand to $\alpha \mathrm{v} \beta 3$ integrin and $\alpha 6 \beta 4$ integrin and direct effects on IGF-1R signaling [175], 
including sustaining of cells during anchorage independence [176] [177]. In their further work, an IGF-1 mutant unable to bind integrins but able to bind IGF-1R had a dominant negative effect on IGF-1R-mediated tumorigenesis in vivo [178], suggesting further functional effects of such ternary complexes.

Together, these data show that integrin activation is able to modify the phosphorylation and signaling from the IGF$1 \mathrm{R}$ and subsequently the biological outcomes. As mentioned before, in addition to RTKs and integrins, members of the GPCR family, can modify the IGF-1R responsiveness to different ligands.

\section{Something borrowed: IGF-1R utilize components of GPCR signaling}

It is generally accepted that RTKs share signaling pathways with the larger class of the GPCRs [3, 179]. Over the last decades, at least two mechanisms of receptor cross-talk between RTKs and GPCRs have been described: receptor transactivation and RTK signaling through GPCR components.

RTK transactivation is typically explained as the GPCRdependent increase in phosphorylation, kinase activity, and signaling of the RTK. One example is represented by the lysophosphatidic acid (LPA) transactivation of the EGFR [180]: LPA, a classical GPCR agonist, triggers EGFR autophosphorylation and MAPK signaling activation, effects that are sensitive to EGFR-kinase inhibitors or expression of EGFR kinase-defective mutants [180]. Although not completely understood, the mechanism of LPA-induced transactivation of EGF receptors is likely to involve the release of an EGFR ligand by a GPCR-activated metalloproteinase. Several other RTKs, including the ones for PDGF, VEGF, and NGF, were reported to be transactivated by GPCR agonists such as LPA, angiotensin, endothelin, and bradykinin (for review, see [179]). It is noteworthy that RTK transactivation by GPCRs required tyrosine phosphorylation and kinase activity of the growth factor receptor and is sensitive to inhibitors of receptor kinases [179, 181]. The IGF-1R is not an exception from this rule: transactivation and phosphorylation of the IGF-1R with subsequent MAPK activation was reported following thrombin stimulation of aortic smooth muscle cells [182]. Several other GPCR-agonists were described as IGF-1R transactivators, including neurotensin [183] and vasopressin [184].

The second mechanism used to explain RTK/GPCR cross-talk is the employment of the GPCR signaling components, G-proteins and $\beta$-arrestins, by the RTKs for their signaling activation. Characteristic of this type of signaling is the response to G-protein signaling inhibitors (e.g., pertussis toxin which uncouples $\mathrm{G} \alpha \mathrm{i}$ from an activated receptor), G-protein sequestration [185], or $\beta$-arrestin downregulation [144, 186]. Most if not all RTKs, including PDGFR, EGFR, and VEGFR, utilize G-proteins as signaling mediators (for in depth reviews, see [3, 179, 181, 187]). In this context, it is worth mentioning that the members of the IR family were the first described to engage the G-proteins signaling: the IR signaling was demonstrated to be sensitive to pertussis toxin treatment [186], with subsequent decrease of the insulin-induced inhibition of adenylyl cyclase in isolated hepatocytes [188]. Several other studies have demonstrated the Gai involvement in IR signaling and their effects on insulin signaling biological outcomes [186, 189]. Given the high structural similarities between IR and IGF-1R, it is not surprising that some G-proteins have also been identified to physically associate and mediate IGF-1R signaling. Almost 20 years ago, a study from Robert Lefkowitz's laboratory reported that IGF-1R-dependent activation of the MAPK signaling pathway was inhibited by the Gai-inhibitor pertussis toxin or by sequestration of G-protein $\beta \gamma$ subunits by a peptide derived from GRK2 [185]. This study clearly demonstrated that IGF-1R signaling depends on heterotrimeric $\mathrm{G}$-proteins containing the $\mathrm{G} \alpha \mathrm{i}$ and $\mathrm{G} \beta \gamma$ subunits. Consistent with these observations, subsequent studies demonstrated that, in rat neuronal cells or mouse fibroblasts, G $\alpha$ i and $\mathrm{G} \beta$ subunits were associated with IGF-1R while $\mathrm{G} \alpha$ s was not associated with the IGF-1R in any cell type. More importantly, this study demonstrated the IGF-1 induced release of the G $\beta$ subunits from the IGF-1R with no effect on IGF-1R/G $\alpha$ i association, indicating a discrete pool of $\mathrm{G} \beta \gamma$ subunits available for IGF-1R downstream signaling [190]. The IGF-1R/G $\alpha$ i association was also reported in a separate study investigating the roles of heterotrimeric G-protein signaling components in insulin and IGF-1 signaling. In 3T3L1 adipocytes, in basal state, G $\alpha$ i and G $\beta$ were associated with the IGF-1R, while IGF-1 stimulation increased the IGF-1R/G $\alpha$ i association, releasing the $G \beta$ subunits [144].

While RTK transactivation by GPCRs has long been recognized and is today considered a "classical" signaling pathway, the complexity of the RTK/GPCR cross-talk was further demonstrated by recent findings of bidirectional cross-communication between RTKs and GPCRs (for in depth reviews, see [181, 187]). In these processes, the GPCR signaling is activated by RTKs by the same two mechanisms described above: production of a GPCR ligand stimulated by RTK activation or a ligand-independent cross-activation of the signaling network [181, 187]. In the case of the IGF-1R, such GPCR-transactivation has been demonstrated to be essential for migratory and prosurvival functions controlled by IGF-1 [181, 187]. Taken together, these studies indicate a common signaling platform between IGF-1R and GPCRs to differentiate between 
the responses upon combined growth factor/GPCR agonist stimulation from single stimulation by either ligand.

The corollary of these studies is that IGF-1R (and IR) can activate signaling as a GPCR, using different G-protein partners for downstream signaling. The G $\alpha$ i subunit is constitutively associated with the IGF-1R while IGF-1 treatment leads to GTP loading of G $\alpha$ i2 [144] and G $\beta \gamma$ dissociation. Yet, these findings raise another critical question: if IGF-1R and IR can activate G-protein signaling, what is the system desensitizing this pathway? In the case of GPCRs, the signaling is terminated by $\beta$-arrestin recruitment to the activated receptor. Early studies demonstrated the involvement of $\beta$-arrestin in IGF-1R signaling and trafficking: a dominant negative mutant of $\beta$-arrestin 1 was demonstrated to impair IGF-1R internalization, whereas overexpression of wild-type $\beta$-arrestin 1 or $\beta$-arrestin 2 increases IGF1R internalization [191]. Moreover, G-protein signaling activated by IGF-1R was demonstrated to be sensitive to $\beta$-arrestin inhibition [144].

The discovery of the dual regulatory role of $\beta$-arrestin 1 in the case of IGF-1R, downregulation [133], and signaling activation [134], pointed towards a remarkable parallel with the role of $\beta$-arrestins in the case of the larger GPCR family. While internalizing the GPCR and ending G-protein signaling, $\beta$-arrestins activate the MAPK pathway [192-194].

Recognized as a universal mechanism of GPCR regulation, $\beta$-arrestin 1 binds to the receptor and desensitizes G-protein signaling only after phosphorylation of specific serine residues by the G-protein-coupled receptor kinases (GRKs) [193, 195, 196]. Therefore, a legitimate question was whether the same mechanism is in place for the IGF-1R.

Investigating this scenario, we found that activated IGF$1 \mathrm{R}$ allows recruitment of the GRK proteins, specifically with contrasting effects between GRK2 and GRK6 [124]. Subsequent GRK2- or GRK6-dependent phosphorylation of IGF-1R C-terminal serine residues 1248 or 1291, respectively, allows $\beta$-arrestin 1 recruitment, with the residue that is phosphorylated controlling the duration and strength of the $\beta$-arrestin/IGF-1R association.

Identification of GRK-dependent phosphorylation of IGF-1R serine residues as the underlying mechanism for $\beta$-arrestin/IGF-1R interaction not only revealed another connection to the complex cross-talk between the IGF-1R and GPCR but in fact provided the missing link to functionally identify IGF-1R as a GPCR. This paradigm shift is founded on the accepted universal model of GPCR activation and desensitization delineated by six distinct processes [195, 197], all of which have been identified to occur for the IGF-1R (Fig. 3): (1) ligand binding to the IGF-1R, in addition to the classical kinase signaling cascade triggers signaling through heterotrimeric G-proteins [144, 185],
(2) subsequent GRK2- or GRK6-dependent phosphorylation of IGF-1R C-terminal serine residues 1248 or 1291, allowing $\beta$-arrestin binding to these specific phosphorylated serine residues [124], with (3) $\beta$-arrestin recruitment $[124,133,134],(4)$ subsequent kinase/G-protein signaling desensitization, (5) activation of a $\beta$-arrestin-dependent second signaling wave through MAPK [124, 134], and (6) receptor endocytosis with the GRK isoform determining receptor degradation [124, 133] or recycling [124]. In this model, one uncertainty is whether, for the IGF-1R, GRK-mediated $\beta$-arrestin binding initiates a desensitization process (Fig. 3, IV) and whether the desensitization process affects both G-protein and kinase signaling. While for GPCRs the key role of GRKs in desensitization is well recognized, for RTKs few studies have investigated the contribution of GRKs [3]. In all published studies, GRK2 is reported to desensitize or modulate RTK signaling. For instance, GRK2 is recruited and co-localizes with the ligand-activated EGFR or PDGFR, leading to receptor serine phosphorylation and increased ERK activation in the case of EGFR [198], or inhibiting the kinase activity in the case of PDGFR [199]. The insulin receptor (IR), closely related to the IGF-1R, is a special case: GRK2 was shown to have inhibitory effects on IR-mediated signaling and glucose uptake, though the observed effects were demonstrated to be mediated in a kinase-independent manner through GRK2 sequestration of G $\alpha \mathrm{q} / 11$ [200].

For GPCRs, the desensitization requires the membrane localization of GRKs. In a palmitoylated state, GRK6 has been found to be exclusively associated with the membrane; however, it is not yet clear whether this reversible posttranslational modification is induced by activated receptor [3]. On the other hand, a clear regulatory negative feedback, induced by activated receptor, was demonstrated for GRK2: G $\beta \gamma$ subunits, generated by the agonist-occupied receptor, interact with GRK2 and serve to target this enzyme into proximity with its membrane receptor substrate [201]. Consequently, $\beta$-arrestin recruitment to GRKphosphorylated receptors physically prevents the coupling of receptor to its cognate G-protein. Thus, a true comparison of IGF-1R desensitization with GPCR desensitization would make sense only if IGF-1R utilizes heterotrimeric G-proteins for its signaling. Our results showing that GRK2 is involved in limiting the ERK response to IGF-1 fully support the GRK2 desensitization function in the case of IGF-1R. For GRK6, our interpretation is that prolonged ERK activation is due to the second wave of signaling activated by the stable $\beta$-arrestin recruitment to the IGF-1R (Fig. 3, V), masking the desensitization of the first signaling wave. Taken together, the proposed model represents IGF-1R as not only "borrowing" components of GPCR signaling but to operate as a functional hybrid RTK/GPCR (Fig. 3). 


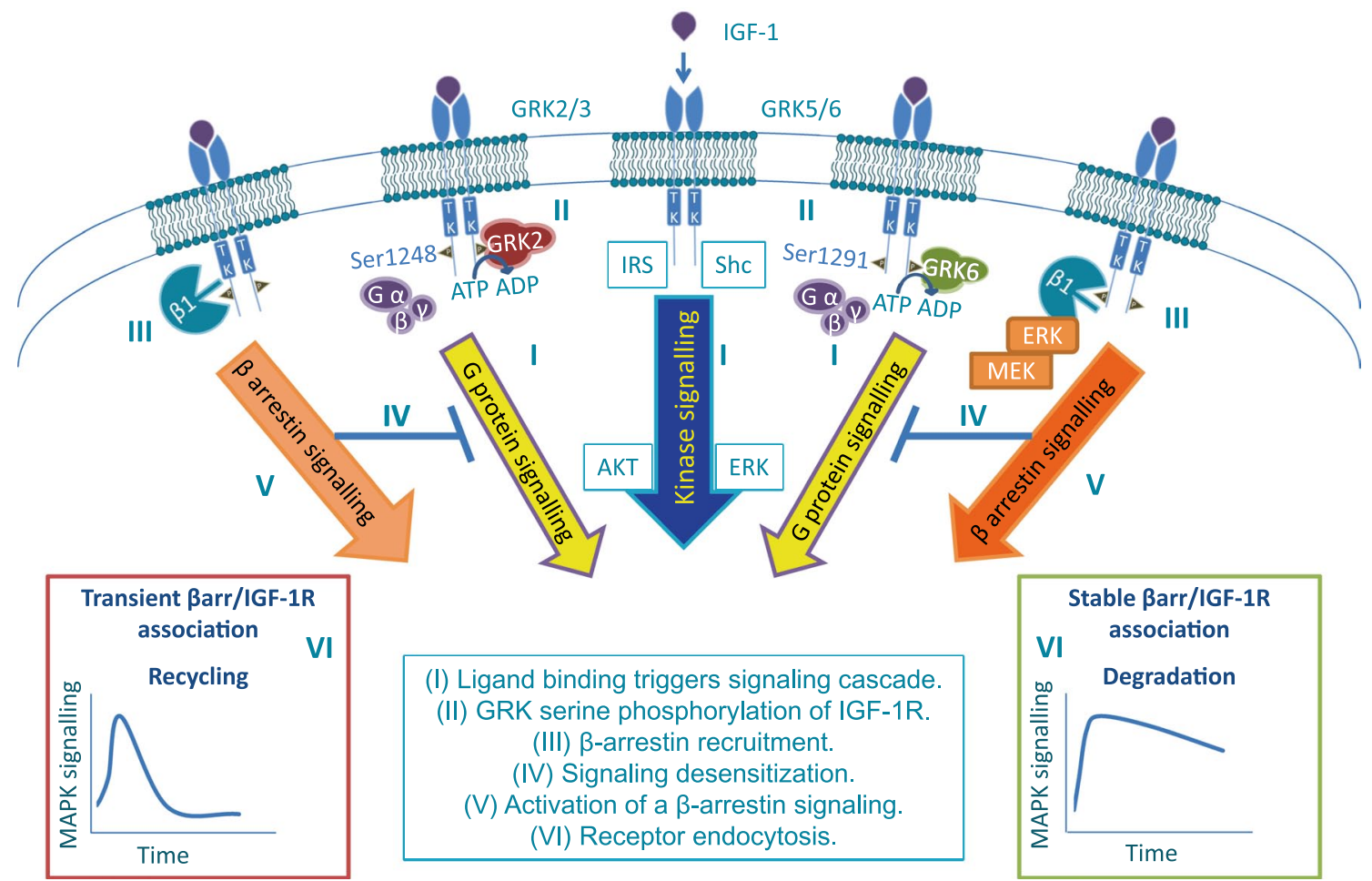

Fig. 3 IGF-1R as a RTK/GPCR functional hybrid. Signaling: agonist-stimulation of the IGF-1R triggers the classical RTK signaling leading to downstream kinase-cascade signaling activation. In addition, agonist-stimulation of IGF-1R leads to non-canonical GPCR signaling through heterotrimeric G-proteins $(\mathrm{G} \alpha, \beta, \gamma)(I)$, following which the receptors are rapidly phosphorylated by G-protein-coupled receptor kinases (GRKs) at serine residues within the C-terminus (II). Desensitization: Serine-phosphorylated receptors present high affinity binding sites to recruit the multifunctional adaptor protein $\beta$-arrestin 1 ( $\beta 1)(I I I)$. Steric binding by $\beta$-arrestin to the IGF-1R C-terminal prevents further G-protein coupling, leading to the desensitization of G-protein-dependent signaling (IV). $\beta$-arrestin signaling: $\beta$-arrestin acquires an active conformation upon binding the IGF-1R and scaffolds components of the MAPK pathways leading to the activation of a second wave of IGF-1R kinase independent signaling through

\section{The emerging paradigm for IGF-1R signaling}

A major limitation of the two-state model for IGF-1R signaling is the explanation of the two main components of the IGF-1R activity: the signaling activation and receptor downregulation as separate events. In this paradigm, all receptors are equal and the receptor activity is exclusively and directly related to kinase activation by ligand-receptor interaction. Signaling, and downregulation triggered simultaneously by the ligand-activated receptor. Both involve phosphorylation, ubiquitination, and probably other posttranslational modifications. The logical conclusion is that receptor signaling and degradation never dissociate from each other or from ligand-induced receptor (kinase) activation. Moreover, in the same cellular context, the MAPK/ ERK and PI3K/Akt pathways are described as being $\beta$-arrestin $1(V)$. The dynamics of this signaling activation is determined by the strength of the $\beta$-arrestin $1 /$ IGF-1R interaction, dependent on GRK-isoform (VI) Such $\beta$-arrestin-dependent MAPK activity has been shown to regulate multiple IGF-1R biological effects including proliferation, apoptosis, cell migration, and cancer metastasis. Endocytosis: agonist-stimulation promotes rapid endocytosis of the IGF-1R. This internalization is enabled by $\beta$-arrestin binding, connecting the receptor to the endocytic machinery efficiently. The interaction between $\beta$-arrestin and the $\mathrm{E} 3$ ubiquitin ligase Mdm2 promotes IGF-1R and $\beta$-arrestin ubiquitination that facilitates IGF-1R endocytosis, followed by post-endocytic sorting of internalized IGF-1R. The strength of the $\beta$-arrestin 1/IGF-1R interaction GRKs-isoformdependent determines the fate of internalized receptor: recycling (transient $\beta$-arrestin 1 binding) or degradation (sustained $\beta$-arrestin 1 binding) $(V I)$

activated in a balanced manner following IGF-1R stimulation. Yet, there is experimental data that do not support this model, including some major contradictions (Table 2) such as kinase-independent signaling activation [124, 134, 202] or unbalanced signaling in the same cellular background [34, 124, 134], signaling-degradation dissociation, or receptor downregulation in the absence of the ligand or activation-loop phosphorylation [37, 124, 203]. Beyond this, there is the major paradox of the IGF-1R inhibitors (antibodies and small molecules inhibitors, see below), which are able to activate IGF-1R downregulation and signaling despite clear inhibitory effects on receptor tyrosine phosphorylation.

The appreciation of the dual functions of $\beta$-arrestin, as a mediator of IGF-1R signaling [124, 134, 191, 204] as well as mediator of receptor downregulation [124, 133], provide 
Table 2 The new paradigm for IGF-1R signaling

\begin{tabular}{|c|c|}
\hline Classical paradigm and its contradictions & Emerging paradigm \\
\hline $\begin{array}{l}\text { Receptor activity is exclusively and directly related to kinase activation } \\
\text { by ligand-receptor interaction }\end{array}$ & $\begin{array}{l}\text { In addition to classical RTK signaling, IGF-1R operates as a functional } \\
\text { GPCR }\end{array}$ \\
\hline $\begin{array}{l}\text { Contradiction: kinase-independent signaling activation: IGF-1R can } \\
\text { trigger MAPK signaling in the absence of the ligand or without } \\
\text { kinase domain activation }[124,134,202]\end{array}$ & $\begin{array}{l}\text { In this model, IGF-1R can initiate kinase-independent signaling such as } \\
\beta \text {-arrestin signaling and heterotrimeric G-protein signaling }\end{array}$ \\
\hline $\begin{array}{l}\text { Signaling and receptor downregulation are triggered simultaneously by } \\
\text { the ligand-activated receptor in a balanced manner } \\
\text { Contradictions: signaling-downregulation dissociation-specific } \\
\text { point-mutations outside the kinase domain can activate signaling or } \\
\text { receptor downregulation in the absence of the ligand or activation- } \\
\text { loop phosphorylation [124] } \\
\text { IGF-1R downregulation induced by ligands other than IGF-1 (e.g., } \\
\text { antibodies) } \\
\text { Unbalanced signaling downregulation induced by IGF-1R transactiva- } \\
\text { tion (e.g., hybrid receptors, integrins, other GPCR or RTKs) }\end{array}$ & $\begin{array}{l}\text { The receptor conformation activating the kinase signaling can be } \\
\text { distinct from that which interacts with } \beta \text {-arrestins facilitating receptor } \\
\text { ubiquitination and endocytosis in the absence of kinase activity } \\
\text { This model can explain the dissociation between kinase activation and } \\
\text { receptor degradation as well as ligand- or kinase-independent signal- } \\
\text { ing or receptor downregulation triggered by kinase inhibitors (e.g., } \\
\text { targeting antibodies) or IGF-1R partners }\end{array}$ \\
\hline $\begin{array}{l}\text { Equal receptors with balanced activation of the downstream signaling } \\
\text { pathways (MAPK/ERK and PI3K/Akt pathways) }\end{array}$ & $\begin{array}{l}\text { The receptor conformation activating the kinase signaling can be dis- } \\
\text { tinct from that which interacts with } \beta \text {-arrestins or with other partners }\end{array}$ \\
\hline $\begin{array}{l}\text { Contradictions: unbalanced signaling: in the same cellular back- } \\
\text { ground, IGF-1R can preferentially activate either the MAPK or } \\
\text { PI3K/AKT pathways }[34,124,134] \\
\text { The paradox of the IGF-1R inhibitors (antibodies and small molecules } \\
\text { inhibitors) which are able to activate IGF-1R signaling despite clear } \\
\text { inhibitory effects on receptor tyrosine phosphorylation }\end{array}$ & $\begin{array}{l}\text { In this model, not all receptors are equal and their activity can be } \\
\text { modulated from inside the cell by particular posttranslational modi- } \\
\text { fications (e.g., serine phosphorylation, ubiquitination, etc.) or by } \\
\text { interacting proteins (e.g., } \beta \text {-arrestins, IR, integrins, etc.) } \\
\text { The same model would also accommodate the unbalanced IGF-1R } \\
\text { signaling, activated in a "biased manner" via } \beta \text {-arrestin by IGF-1R } \\
\text { inhibitors as well as by natural "biased" agonists }\end{array}$ \\
\hline
\end{tabular}

The contradictory evidence against the two-state model is described and how the new paradigm can explain these data

the basis for the emerging paradigm of IGF-1R signaling. In this model, IGF-1R can initiate classical kinase signaling, $\beta$-arrestin signaling, and heterotrimeric G-protein signaling as well as $\beta$-arrestin-mediated receptor desensitization (Fig. 4). However, the receptor conformation activating the kinase signaling can be distinct from that which interacts with $\beta$-arrestins, as demonstrated by the IGF-1R mutants constitutively binding $\beta$-arrestin, that are degraded even in the absence of the ligand [124] (Fig. 4). This scenario can explain the dissociation between kinase activation and receptor degradation as well as kinase-independent signaling. The same model would also accommodate the unbalanced IGF-1R signaling, activated in a "biased manner" via $\beta$-arrestin by IGF-1R inhibitors as well as by natural "biased" agonists [22, 143]. In this emerging model, not all receptors are equal and their activity can be modulated from inside the cell by particular posttranslational modifications (e.g., serine phosphorylation, ubiquitination, etc.) or by interacting proteins (e.g., $\beta$-arrestins, integrins, other RTKs).

\section{Implications for treatment}

Owing to its essential role in maintaining the malignant phenotype, IGF-1R-targeted therapy was considered a very promising strategy for cancer treatment [205-214].
Although several approaches targeting the IGF-1R were employed to prove the concept, the common aim for all these strategies is the inhibition of the classical kinase signaling cascade (for reviews, see [26, 27, 91, 215]). This can be accomplished either by preventing ligand-receptor interaction (e.g., using blocking antibodies) or silencing the effects of this interaction (e.g., tyrosine kinase inhibitors, TKIs).

Strategies aimed at blocking the ligand-receptor interaction

Receptor downregulation was among the first approaches used to prevent ligand-receptor interaction and to validate IGF-1R as a therapeutic target [216]. This was achieved by antisense oligonucleotides, plasmids expressing IGF$1 \mathrm{R}$ antisense cDNA or triple helix-forming oligodeoxynucleotides [23]. The same outcome was obtained with drugs interfering with IGF-1R glycosylation, folding and expression at the cell surface (tunicamycin or lovastatin) $[17-19,217]$ or by directly increasing receptor degradation $[114,218]$. The majority of these systems were unsuitable for transfer to the clinic, either because they were unable to be delivered or because they were too unspecific, so the next work in this area focused on clinically suitable methods for blocking the ligand-receptor interaction. 

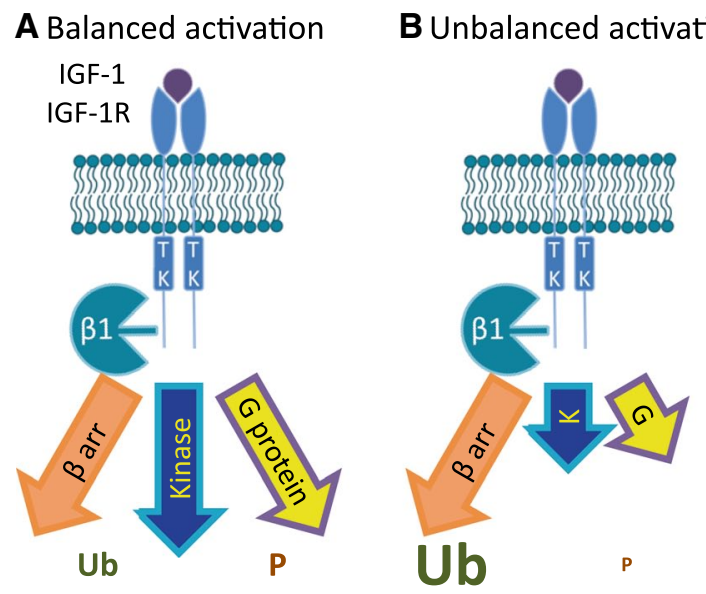

Increased $\beta$-arr signalling

Biased agonists:

- Antibodies

- Small molecule inhibitor

- LL37

Biased receptors:

- IGF-1R S1248A

- IGF-1R S1291D

- IGF-1R A-loop mutant

- GPCR transactivation?

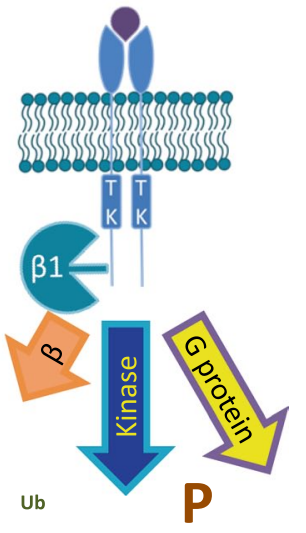

Decreased $\beta$-arr signalling

Biased ligands:

- GPCRs agonists?

- EGF transactivation

Biased receptors:

- IGF-1R $\Delta 1245$

- IGF-1R 1248D

- IGF-1R 1291A

- IGF-1R/IR hybrid?
Fig. 4 New and old paradigms of IGF-1R signaling: balanced and biased signaling at the IGF-1R. a Classical model: IGF-1R activation is triggered exclusively by ligand-binding and signaling is mediated by kinase cascade through phosphorylation. Ligand-activated IGF$1 \mathrm{R}$ leads to balanced phosphorylation-dependent Akt/ERK signaling and balanced signaling/downregulation. b New paradigm. In the current model for IGF-1R activation, in addition to the classical RTK-cascade, binding of a ligand results in activation of signaling by $\mathrm{G}$-proteins and $\beta$-arrestins, as well as desensitization and internalization by $\beta$-arrestins. In a system with balanced signaling, ligandbinding results in balanced activation of kinase signaling, signaling

Competition with the ligand-receptor interaction

In this category are included strategies that involve upregulation of the IGFBPs, the natural IGF inhibitors [219], IGFs peptide analogues $[219,220]$, or ligand or receptor neutralizing antibodies $[206,221]$. There are seven different IGFBPs, most of them have been shown to inhibit the actions of IGFs. In vitro and in vivo experiments indicate that increasing IGFBPs could be an alternative to IGF$1 \mathrm{R}$ targeting, particularly due to the lack of interference with insulin signaling [222]. There is also evidence that free IGFBPs have anti-tumor activity independent of their IGF-binding capacity [223]. Anti-ligand antibodies, developed to mimic IGFBP action, have a high affinity against both IGF-1 and IGF-2, and do not cross-react with insulin [224-226]. Several antibodies targeting IGF-1 or IGF-2 have been reported, with one reaching clinical trial [225]. by G-proteins and $\beta$-arrestins, as well as desensitization and internalization by $\beta$-arrestin. In a system with biased signaling, two alternative outcomes of receptor activation are depicted: kinase/G-proteinbiased with enhanced IGF-1R phosphorylation and $\beta$-arrestin-biased with enhanced IGF-1R ubiquitination. Biased signaling is a feature of the ligand-receptor complex so either the receptor or the ligand could be biased. An IGF-1R biased ligand elicits one response over another compared with the classical ligand, (e.g., anti-IGF-1R favors $\beta$-arrestin signaling). A biased IGF-1R is only efficient at activating a restricted subset of downstream signaling pathways (e.g., mutant receptors)

They prevent signaling through the IGF-1R and the hybrid receptors, but, importantly, they do not affect insulin-stimulated phosphorylation of the insulin receptor (IR) and its downstream signaling. While most of the ligand-targeting antibodies bind to both IGFs, a few have higher affinity for IGF-2 [224, 226, 227]. Notably, antibody sequestration of ligand can lead to high levels of free IGFBPs, a consequence that might improve their intended effect [93].

Antibodies against the extracellular ligand binding domain of the IGF-1R were designed to block ligandreceptor interaction $[27,93]$. This strategy was considered to be very promising, and therefore most of the large pharmaceutical companies developed anti-IGF-1R antibodies and those demonstrating significant activity in preclinical settings were taken forward for clinical evaluation [27, 93]. However, in clinical settings, treatment with anti-IGF-1R antibodies induced clinical responses only in some cases 
of Ewing's sarcoma (ES) [228-230] and selected cases of lung carcinoma [93, 231, 232]. Although not chosen by design, all anti-IGF-1R antibodies used in clinical trials, besides inhibiting IGF-1-induced receptor phosphorylation, also trigger receptor downregulation ([140] and below).

\section{Strategies aiming to inhibit IGF-1R signaling}

The proof of mechanism for this approach is represented by IGF-1R kinase-dominant negative mutants, successfully tested in preclinical settings by several laboratories $[211,233]$. Cells transfected to express IGF-1R cDNA with kinase-inactivating [234] or kinase-limiting mutations [235, 236], lose their malignant phenotype as well as their invasive and metastatic potential [237]. The promising strategy of inhibiting IGF-1R kinase activity is complicated by IR cross-reactivity issues, as the kinase domain of the IGF-1R shares $85 \%$ homology with that of the IR, with the ATP binding cleft $100 \%$ conserved [40]. Nevertheless, several small inhibitors have been developed (for review [238, 239]) and despite some of them having shown signs of cross-reactivity with the IR, they are still considered for use in clinical settings. Additionally, there is recent evidence and debate in the literature as to whether co-inhibition of the IR is beneficial for anti-IGF-1R therapy [240, 241]. While all small molecules targeting IGF-1R prevent kinase activation, they can be further divided in two subgroups, based on their mechanism of action: inhibitors of the ATP binding cleft or inhibitors of the kinase-substrate interaction, including inhibitors of the A-loop. Among the first category, NVP-AEW541 and NVP-ADW74 inhibit IGF-1R kinase activity and appear to be equipotent for both IGF-1R and IR inhibition in vitro, yet they show selectivity for the IGF-1R in intact cells. The two drugs were tested in various models such as fibrosarcoma, myeloma, and ES [242, 243]. Another small molecule, OSI-906 is a dual IGF-1R/IR kinase inhibitor with a strong anti-tumoral efficiency in an IGF-IR-driven xenograft model [244]. There have been several such inhibitors tested in clinical trials [27], and what they have in common is that inhibition of the ATPbinding also prevents IGF-1R downregulation. This is not surprising as in vitro experiments clearly demonstrated that IGF-1R ATP-defective mutants are not ubiquitinated [121].

Among the second category of the IGF-1R kinase inhibitors (TKIs), the cyclolignan picropodophyllin (PPP) demonstrates a special feature for this class. PPP was originally described to inhibit the IGF-1R without altering the IR, reducing Akt phosphorylation [20] and inducing tumor regression in xenografted mice. Rather than competing with ATP, PPP differs from other IGF-1R TKIs by interfering with phosphorylation of the kinase domain A-loop. PPP specifically blocked phosphorylation of the tyrosine (Y) 1136 residue, while sparing the two others (Y1131 and
Y1135), suggesting that it might act as a substrate inhibitor [245]. Since its discovery [20], PPP has been proven to inhibit IGF-1R biological activities in a very large number of experimental models as well as in clinical settings $[14,16,24,90,246-258]$, has been demonstrated to produce very limited resistance $[22,259,260]$ to anti-IGF-1R therapy, and has proven efficacy in clinical trials [261]. The remarkable feature of PPP that differentiates it from ATPinhibitors is that, similar to anti-IGF-1R antibodies, PPP also triggers IGF-1R downregulation [143]. This feature deserves special attention because it supports the logical but still contentious [90] assumption that receptor downregulation is desirable in addition to inhibition of its TK activity $[15,95]$.

Yet, the debate on how important receptor downregulation is in relation to kinase inhibition is hiding a paradox: how is the receptor downregulated by inhibiting its kinase activity?

The classical, binary ON/OFF model for IGF-1R signaling and degradation implies that the only way to maintain the receptor in an 'OFF' state is by preventing kinase activity while degradation would only occur with an 'ON' state receptor. Evidently this model is insufficient, because it cannot account for the contradiction that anti-IGF-1R antibodies (or PPP) trigger receptor degradation in the absence of kinase activation. This contradiction was recently investigated for the case of anti-IGF-1R antibody (Figitumumab)induced receptor degradation [140]. Although the antibodies were primarily designed to block the ligand-receptor interaction thus preventing kinase activity, it has been demonstrated that targeting antibodies act as "biased" IGF-1R agonists, activating $\beta$-arrestin recruitment to the receptor, with subsequent receptor ubiquitination, internalization, ERK signaling activation, and IGF-1R degradation [140]. In agreement with this, anti-IGF-1R therapy efficacy was proven to be highly dependent on $\beta$-arrestin 1 expression and modulated by co-targeting $\beta$-arrestin 1 -mediated signaling [140]. Notably, a similar mechanism of $\beta$-arrestin 1-mediated receptor ubiquitination and downregulation with activation of the $\beta$-arrestin 1/ERK second signaling wave has also been demonstrated in the case of the PPP paradox [143].

The experimental data provided by these studies fully substantiate and support the new paradigm for IGF-1R signaling which allows for unbalanced signaling and kinase activation/receptor downregulation dichotomy (Fig. 4). According to this model, the conformation of IGF-1R, which activates the kinase cascade, can be distinct from that which interacts with $\beta$-arrestins or other signaling molecules. Receptor modification induced by ligands, small molecule inhibitors, or intra-cellular interacting proteins can further be interpreted as alterations to the IGF-1R conformation, there being more than just two 
(ON/OFF) conformations. Different conformations can be mutually exclusive and can determine the quality, quantity, and duration of output signaling from the receptor as well as the fate of the receptor (Fig. 4). Recognizing the dual role of $\beta$-arrestin in controlling receptor downregulation as well as kinase-independent signaling, the new model we propose (Fig. 4) can accommodate all experimental data, demonstrating that IGF-1R signaling is not exclusively dependent on its kinase activity and can be activated and downregulated in a "biased" manner via $\beta$-arrestin 1 by IGF-1R inhibitors or by natural "biased" agonists [143, 253] (Table 2). In the emerging model of IGF-1R signaling, the question of "how important receptor is downregulation in relation to kinase inhibition?" is getting a new meaning: "Is it possible to downregulate the IGF-1R without activating signaling?" As downregulation without signaling has never been recognized, a simpler solution would be to identify the biased signaling pathways and target them separately [140].

Although oversimplified and insufficient to explain several outcomes of IGF-1R activation, the classical paradigm is currently in use when selecting the agents targeting the IGF-1R. The best example is the case of anti-IGF-1R antibody: during their development, antibodies were designed to achieve the maximum binding to IGF-1R, to compete with the natural agonists [140]. In the subsequent drug screening for clonal selection, the assays were limited to confirmation of their inhibitory effects on IGF-1-induced receptor signaling [142, 262-265]. As long as the canonical IGF-1R model does not acknowledge kinase-independent signaling, it is not surprising that targeting antibodies were rarely evaluated in IGF-1-independent conditions to estimate their intrinsic agonistic potential: most measuring receptor phosphorylation, a few checking IRS/Akt activation, and none checking MAPK/ERK activity.

Despite big expectations regarding the use of anti-IGF$1 \mathrm{R}$ for cancer treatment, almost all clinical trials were stopped due to futility, whereas some pharmaceutical companies closed their programs for developing IGF-1R inhibitors [93]. Furthermore, the value of IGF-1R as a target for cancer therapy has been questioned [90, 93]. While several reasons for the failure of the anti-IGF-1R have already been discussed in detail [90, 93], the new paradigm we propose for the IGF-1R signaling highlights another potential cause for these unsatisfactory results: biased-signaling activation by anti-IGF-1R antibodies. The best example is again Figitumumab, designed to prevent the IGF-1 binding to its receptor and kinase-dependent signaling. In Ewing sarcoma, at least two resistance mechanisms have been reported, developed after Figitumumab treatment: formation of the IGF-1R/IR hybrid receptors [266] and biased IGF-1R signaling activation [140]. As described before, the IGF-1R/IR hybrid formation could be appreciated as a form of receptor bias. Challenging the classical two-state model in which the antibodies were designed, the new paradigm in which a biased-receptor (IGF-1R/IR hybrid) is activated by a biased-agonist (Figitumumab) provides an explanation as to why such a strategy did not work in clinical settings and advocates recognition of IGF-1R as a key target for cancer therapy and a clear choice for the baby rather than the bathwater [91].

\section{Concluding remarks}

Today, targeting the IGF-IR and components of its signaling pathway in different forms of cancer is a major research area. Yet, the design of such targeting agents is based mostly on the classical ON/OFF model of IGF-1R activation. The present review highlights the fact that, in addition to the classical kinase pathway, IGF-1R activity and its biological effects are controlled by a variety of adaptor/ signaling-proteins through IGF-1R posttranslational modifications, including tyrosine and serine phosphorylation, de-phosphorylation, ubiquitination, and sumoylation. The complexity of IGF-1R behavior following exposure to IGF$1 \mathrm{R}$ inhibitors reinforces the need to understand the relationships between different signaling pathways and between signaling and degradation. Only this can lead to the rational design and testing of IGF-1R inhibitors and the successful combining of these therapeutics with others targeting parallel pathways. Searching for therapies inhibiting only IGF$1 \mathrm{R}$ kinase activity may appear to invalidate the IGF-1R as a target for cancer therapy, while many potential drugs that modify alternative downstream effects, the "biasing agonists", are not considered.

Acknowledgments Research support was received from the Swedish Cancer Society, Swedish Research Council, The Swedish Childhood Cancer Foundation, Crown Princess Margareta's Foundation for the Visually Impaired, Welander Finsen Foundation, King Gustaf V Jubilee Foundation, Vinnova, Stockholm Cancer Society, Stockholm County, and Karolinska Institute. To S. -I. T., Grants-in-Aid for Scientific Research (\#25221204), a Grant-in Aid for International Joint Research and Core-to-Core Program from the Japan Society for the Promotion of Science.

Open Access This article is distributed under the terms of the Creative Commons Attribution License which permits any use, distribution, and reproduction in any medium, provided the original author(s) and the source are credited.

\section{References}

1. Lemmon MA, Schlessinger J (2010) Cell signaling by receptor tyrosine kinases. Cell 141(7):1117-1134

2. Aaronson SA (1991) Growth factors and cancer. Science 254(5035):1146-1153 
3. Hupfeld CJ, Olefsky JM (2007) Regulation of receptor tyrosine kinase signaling by GRKs and beta-arrestins. Annu Rev Physiol 69:561-577

4. Ullrich A, Schlessinger J (1990) Signal transduction by receptors with tyrosine kinase activity. Cell 61(2):203-212

5. Weiss A, Schlessinger J (1998) Switching signals on or off by receptor dimerization. Cell 94(3):277-280

6. Heldin CH (1995) Dimerization of cell surface receptors in signal transduction. Cell 80(2):213-223

7. Heldin CH, Ostman A (1996) Ligand-induced dimerization of growth factor receptors: variations on the theme. Cytokine Growth Factor Rev 7(1):3-10

8. Lemmon MA, Schlessinger J (1994) Regulation of signal transduction and signal diversity by receptor oligomerization. Trends Biochem Sci 19(11):459-463

9. Carraway KL 3rd, Cantley LC (1994) A neu acquaintance for erbB3 and erbB4: a role for receptor heterodimerization in growth signaling. Cell 78(1):5-8

10. Schlessinger J (1997) Direct binding and activation of receptor tyrosine kinases by collagen. Cell 91(7):869-872

11. Ullrich A et al (1984) Human epidermal growth factor receptor cDNA sequence and aberrant expression of the amplified gene in A431 epidermoid carcinoma cells. Nature 309(5967):418-425

12. Roberts PJ, Der CJ (2007) Targeting the Raf-MEK-ERK mitogen-activated protein kinase cascade for the treatment of cancer. Oncogene 26(22):3291-3310

13. Sell C et al (1994) Effect of a null mutation of the insulin-like growth factor I receptor gene on growth and transformation of mouse embryo fibroblasts. Mol Cell Biol 14(6):3604-3612

14. Girnita A et al (2006) The insulin-like growth factor-I receptor inhibitor picropodophyllin causes tumor regression and attenuates mechanisms involved in invasion of uveal melanoma cells. Clin Cancer Res 12(4):1383-1391

15. Baserga R, Peruzzi F, Reiss K (2003) The IGF-1 receptor in cancer biology. Int J Cancer 107(6):873-877

16. Economou MA et al (2008) Inhibition of VEGF secretion and experimental choroidal neovascularization by picropodophyllin (PPP), an inhibitor of the insulin-like growth factor-1 receptor. Invest Ophthalmol Vis Sci 49(6):2620-2626

17. All-Ericsson $\mathrm{C}$ et al (2002) Insulin-like growth factor-1 receptor in uveal melanoma: a predictor for metastatic disease and a potential therapeutic target. Invest Ophthalmol Vis Sci 43(1):1-8

18. Girnita L et al (2000) Inhibition of N-linked glycosylation down-regulates insulin-like growth factor-1 receptor at the cell surface and kills Ewing's sarcoma cells: therapeutic implications. Anticancer Drug Des 15(1):67-72

19. Wang $M$ et al (1999) Regulatory role of mevalonate and $\mathrm{N}$-linked glycosylation in proliferation and expression of the EWS/FLI-1 fusion protein in Ewing's sarcoma cells. Exp Cell Res 246(1):38-46

20. Girnita A et al (2004) Cyclolignans as inhibitors of the insulinlike growth factor-1 receptor and malignant cell growth. Cancer Res 64(1):236-242

21. Ulfarsson E et al (2005) Expression and growth dependency of the insulin-like growth factor I receptor in craniopharyngioma cells: a novel therapeutic approach. Clin Cancer Res 11(13):4674-4680

22. Vasilcanu D et al (2006) The insulin-like growth factor-1 receptor inhibitor PPP produces only very limited resistance in tumor cells exposed to long-term selection. Oncogene 25(22):3186-3195

23. Baserga R (2005) The insulin-like growth factor-I receptor as a target for cancer therapy. Expert Opin Ther Targets 9(4):753-768
24. Yin $\mathrm{S}$ et al (2010) Targeting the insulin-like growth factor-1 receptor by picropodophyllin as a treatment option for glioblastoma. Neuro Oncol 12(1):19-27

25. Furukawa $\mathbf{J}$ et al (2010) Antisense oligonucleotide targeting of insulin-like growth factor-1 receptor (IGF-1R) in prostate cancer. Prostate. 70(2):206-218

26. Gualberto A, Pollak M (2009) Clinical development of inhibitors of the insulin-like growth factor receptor in oncology. Curr Drug Targets 10(10):923-936

27. Gualberto A, Pollak M (2009) Emerging role of insulin-like growth factor receptor inhibitors in oncology: early clinical trial results and future directions. Oncogene 28(34):3009-3021

28. Tornkvist $M$ et al (2008) Differential roles of SS18-SSX fusion gene and insulin-like growth factor-1 receptor in synovial sarcoma cell growth. Biochem Biophys Res Commun 368(3):793-800

29. Girnita L et al (2000) Increased expression of insulin-like growth factor I receptor in malignant cells expressing aberrant p53: functional impact. Cancer Res 60(18):5278-5283

30. Beauchamp MC et al (2010) Targeting insulin and insulin-like growth factor pathways in epithelial ovarian cancer. J Oncol 2010:257058

31. Jones JI, Clemmons DR (1995) Insulin-like growth factors and their binding-proteins: biological actions. Endocr Rev 16(1):3-34

32. Nakae J, Kido Y, Accili D (2001) Distinct and overlapping functions of insulin and IGF-I receptors. Endocr Rev 22(6):818-835

33. Adams TE et al (2000) Structure and function of the type 1 insulin-like growth factor receptor. Cell Mol Life Sci 57(7):1050-1093

34. Girnita A et al (2011) Identification of the cathelicidin peptide LL-37 as agonist for the type I insulin-like growth factor receptor. Oncogene 31(3):352-365

35. Petrenko AG et al (2013) Insulin receptor-related receptor as an extracellular $\mathrm{pH}$ sensor involved in the regulation of acid-base balance. Biochim Biophys Acta 1834(10):2170-2175

36. Bailyes EM et al (1997) Insulin receptor/IGF-I receptor hybrids are widely distributed in mammalian tissues: quantification of individual receptor species by selective immunoprecipitation and immunoblotting. Biochem J 327(Pt 1):209-215

37. Belfiore A et al (2009) Insulin receptor isoforms and insulin receptor/insulin-like growth factor receptor hybrids in physiology and disease. Endocr Rev 30(6):586-623

38. Evdokimova V et al (2012) IGFBP7 binds to the IGF-1 receptor and blocks its activation by insulin-like growth factors. Sci Signal 5(255):ra92

39. Sepp-Lorenzino L (1998) Structure and function of the insulin-like growth factor I receptor. Breast Cancer Res Treat 47(3):235-253

40. Ullrich A et al (1986) Insulin-like growth factor I receptor primary structure: comparison with insulin receptor suggests structural determinants that define functional specificity. EMBO J 5(10):2503-2512

41. LeRoith D et al (1995) Molecular and cellular aspects of the insulin-like growth factor I receptor. Endocr Rev 16(2):143-163

42. Andersen AS et al (1990) Changing the insulin receptor to possess insulin-like growth factor I ligand specificity. Biochemistry 29(32):7363-7366

43. Gustafson TA, Rutter WJ (1990) The cysteine-rich domains of the insulin and insulin-like growth factor I receptors are primary determinants of hormone binding specificity. Evidence from receptor chimeras. J Biol Chem 265(30):18663-18667

44. Kjeldsen $\mathrm{T}$ et al (1991) The ligand specificities of the insulin receptor and the insulin-like growth factor I receptor reside in different regions of a common binding site. Proc Natl Acad Sci USA 88(10):4404-4408 
45. Schumacher R et al (1991) Insulin and insulin-like growth factor-1 binding specificity is determined by distinct regions of their cognate receptors. J Biol Chem 266(29):19288-19295

46. Zhang B, Roth RA (1991) Binding properties of chimeric insulin receptors containing the cysteine-rich domain of either the insulin-like growth factor I receptor or the insulin receptor related receptor. Biochemistry 30(21):5113-5117

47. Brown MS, Goldstein JL (1986) A receptor-mediated pathway for cholesterol homeostasis. Science 232(4746):34-47

48. Backer JM et al (1990) Receptor-mediated internalization of insulin requires a 12-amino acid sequence in the juxtamembrane region of the insulin receptor beta-subunit. J Biol Chem 265(27):16450-16454

49. Hsu D et al (1994) NPXY motif in the insulin-like growth factor-I receptor is required for efficient ligand-mediated receptor internalization and biological signaling. Endocrinology 134(2):744-750

50. Prager D et al (1994) Human insulin-like growth factor I receptor internalization. Role of the juxtamembrane domain. J Biol Chem 269(16):11934-11937

51. Hanks SK, Quinn AM, Hunter T (1988) The protein kinase family: conserved features and deduced phylogeny of the catalytic domains. Science 241(4861):42-52

52. O'Connor R, Fennelly C, Krause D (2000) Regulation of survival signals from the insulin-like growth factor-I receptor. Biochem Soc Trans 28(2):47-51

53. Patti ME, Kahn CR (1998) The insulin receptor-a critical link in glucose homeostasis and insulin action. J Basic Clin Physiol Pharmacol 9(2-4):89-109

54. Blakesley VA et al (1996) Signaling via the insulin-like growth factor-I receptor: does it differ from insulin receptor signaling? Cytokine Growth Factor Rev 7(2):153-159

55. Lammers $\mathrm{R}$ et al (1989) Differential signaling potential of insulin- and IGF-1-receptor cytoplasmic domains. EMBO J 8(5):1369-1375

56. Favelyukis $\mathrm{S}$ et al (2001) Structure and autoregulation of the insulin-like growth factor 1 receptor kinase. Nat Struct Biol 8(12):1058-1063

57. Wang LM et al (1993) IRS-1: essential for insulin- and IL4-stimulated mitogenesis in hematopoietic cells. Science 261(5128):1591-1594

58. Goel HL et al (2004) Selective modulation of type 1 insulin-like growth factor receptor signaling and functions by beta1 integrins. J Cell Biol 166(3):407-418

59. Fukushima $T$ et al (2011) Insulin receptor substrates form highmolecular-mass complexes that modulate their availability to insulin/insulin-like growth factor-I receptor tyrosine kinases. Biochem Biophys Res Commun 404(3):767-773

60. Yoshihara $\mathrm{H}$ et al (2012) Insulin/insulin-like growth factor (IGF) stimulation abrogates an association between a deubiquitinating enzyme USP7 and insulin receptor substrates (IRSs) followed by proteasomal degradation of IRSs. Biochem Biophys Res Commun 423(1):122-127

61. Wills MK, Jones N (2012) Teaching an old dogma new tricks: twenty years of Shc adaptor signaling. Biochem J 447(1):1-16

62. Werner H, Le Roith D (2000) New concepts in regulation and function of the insulin-like growth factors: implications for understanding normal growth and neoplasia. Cell Mol Life Sci 57(6):932-942

63. Fukushima T et al (2012) Phosphatidylinositol 3-kinase (PI3K) activity bound to insulin-like growth factor-I (IGF-I) receptor, which is continuously sustained by IGF-I stimulation, is required for IGF-I-induced cell proliferation. J Biol Chem 287(35):29713-29721

64. Alessi DR et al (1996) Mechanism of activation of protein kinase B by insulin and IGF-1. EMBO J 15(23):6541-6551
65. Balendran A et al (1999) Evidence that 3-phosphoinositidedependent protein kinase-1 mediates phosphorylation of p70 S6 kinase in vivo at Thr-412 as well as Thr-252. J Biol Chem 274(52):37400-37406

66. del Peso L et al (1997) Interleukin-3-induced phosphorylation of BAD through the protein kinase Akt. Science 278(5338):687-689

67. Cardone MH et al (1998) Regulation of cell death protease caspase-9 by phosphorylation. Science 282(5392):1318-1321

68. Dupont J et al (2003) The insulin-like growth factor axis in cell cycle progression. Horm Metab Res 35(11-12):740-750

69. Blume-Jensen P, Hunter T (2001) Oncogenic kinase signaling. Nature 411(6835):355-365

70. Zhang D et al (2004) Dual regulation of MMP-2 expression by the type 1 insulin-like growth factor receptor: the phosphatidylinositol 3-kinase/Akt and Raf/ERK pathways transmit opposing signals. J Biol Chem 279(19):19683-19690

71. Mayo LD, Donner DB (2001) A phosphatidylinositol 3-kinase/Akt pathway promotes translocation of Mdm2 from the cytoplasm to the nucleus. Proc Natl Acad Sci USA 98(20):11598-11603

72. Peeper DS et al (1997) Ras signaling linked to the cellcycle machinery by the retinoblastoma protein. Nature 386(6621):177-181

73. Bates $\mathrm{S}$ et al (1998) p14ARF links the tumour suppressors RB and p53. Nature 395(6698):124-125

74. Sherr CJ, Weber JD (2000) The ARF/p53 pathway. Curr Opin Genet Dev 10(1):94-99

75. Marchetti A et al (2004) p53 can inhibit cell proliferation through caspase-mediated cleavage of ERK2/MAPK. Cell Death Differ 11(6):596-607

76. Walsh S, Margolis SS, Kornbluth S (2003) Phosphorylation of the cyclin b1 cytoplasmic retention sequence by mitogen-activated protein kinase and Plx. Mol Cancer Res 1(4):280-289

77. Strausfeld U et al (1991) Dephosphorylation and activation of a p34cdc2/cyclin B complex in vitro by human CDC25 protein. Nature 351(6323):242-245

78. Morrione A et al (1996) Grb10: a new substrate of the insulinlike growth factor I receptor. Cancer Res 56(14):3165-3167

79. Wang J et al (1999) Grb10, a positive, stimulatory signaling adapter in platelet-derived growth factor BB-, insulin-like growth factor I-, and insulin-mediated mitogenesis. Mol Cell Biol 19(9):6217-6228

80. Uddin S et al (1996) Insulin-like growth factor-1 induces rapid tyrosine phosphorylation of the vav proto-oncogene product. Exp Hematol 24(5):622-627

81. Zeng L et al (2000) Vav3 mediates receptor protein tyrosine kinase signaling, regulates GTPase activity, modulates cell morphology, and induces cell transformation. Mol Cell Biol 20(24):9212-9224

82. Beitner-Johnson D, LeRoith D (1995) Insulin-like growth factor-I stimulates tyrosine phosphorylation of endogenous c-Crk. J Biol Chem 270(10):5187-5190

83. Baron V et al (1998) p125Fak focal adhesion kinase is a substrate for the insulin and insulin-like growth factor-I tyrosine kinase receptors. J Biol Chem 273(12):7162-7168

84. Seely BL et al (1995) Localization of the insulin-like growth factor I receptor binding sites for the $\mathrm{SH} 2$ domain proteins p85, Syp, and GTPase activating-protein. J Biol Chem 270(32):19151-19157

85. Arbet-Engels C, Tartare-Deckert S, Eckhart W (1999) C-terminal Src kinase associates with ligand-stimulated insulin-like growth factor-I receptor. J Biol Chem 274(9):5422-5428

86. Dey BR et al (1998) Interaction of human suppressor of cytokine signaling (SOCS)-2 with the insulin-like growth factor-I receptor. J Biol Chem 273(37):24095-24101 
87. Hermanto U et al (2002) RACK1, an insulin-like growth factor I (IGF-I) receptor-interacting protein, modulates IGF-I-dependent integrin signaling and promotes cell spreading and contact with extracellular matrix. Mol Cell Biol 22(7):2345-2365

88. Kiely PA, Sant A, O'Connor R (2002) RACK1 is an insulin-like growth factor 1 (IGF-1) receptor-interacting protein that can regulate IGF-1-mediated Akt activation and protection from cell death. J Biol Chem 277(25):22581-22589

89. O'Connor R et al (1997) Identification of domains of the insulin-like growth factor I receptor that are required for protection from apoptosis. Mol Cell Biol 17(1):427-435

90. Baserga R (2012) The decline and fall of the IGF-I receptor. J Cell Physiol 228(4):675-679

91. Yee D (2012) Insulin-like growth factor receptor inhibitors: baby or the bathwater? J Natl Cancer Inst 104(13):975-981

92. Werner H (2012) Tumor suppressors govern insulin-like growth factor signaling pathways: implications in metabolism and cancer. Oncogene 31(22):2703-2714

93. Pollak M (2012) The insulin and insulin-like growth factor receptor family in neoplasia: an update. Nat Rev Cancer 12(3):159-169

94. LeRoith D, Roberts CT Jr (2003) The insulin-like growth factor system and cancer. Cancer Lett 195(2):127-137

95. Larsson O, Girnita A, Girnita L (2005) Role of insulin-like growth factor 1 receptor signaling in cancer. $\mathrm{Br} \mathrm{J}$ Cancer 92(12):2097-2101

96. Pearse BM, Robinson MS (1990) Clathrin, adaptors, and sorting. Annu Rev Cell Biol 6:151-171

97. Robinson MS (1989) Cloning of cDNAs encoding two related 100-kD coated vesicle proteins (alpha-adaptins). J Cell Biol 108(3):833-842

98. Koenig JA, Edwardson JM (1997) Endocytosis and recycling of G-protein-coupled receptors. Trends Pharmacol Sci 18(8):276-287

99. Hicke L (1997) Ubiquitin-dependent internalization and down-regulation of plasma membrane proteins. FASEB J 11(14):1215-1226

100. Hicke L (1999) Gettin' down with ubiquitin: turning off cellsurface receptors, transporters and channels. Trends Cell Biol 9(3):107-112

101. Hicke L (2001) Protein regulation by monoubiquitin. Nat Rev Mol Cell Biol 2(3):195-201

102. Haglund K, Dikic I (2012) The role of ubiquitylation in receptor endocytosis and endosomal sorting. J Cell Sci $125(\mathrm{Pt}$ 2):265-275

103. Andersson ER (2011) The role of endocytosis in activating and regulating signal transduction. Cell Mol Life Sci 69(11):1755-1771

104. Luo Y et al (2011) Endosomal signaling of epidermal growth factor receptors contributes to EGF-stimulated cell cycle progression in primary hepatocytes. Eur $\mathrm{J}$ Pharmacol 654(2):173-180

105. Huynh $\mathrm{J}$ et al (2012) CSF-1 receptor signaling from endosomes mediates the sustained activation of Erk1/2 and Akt in macrophages. Cell Signal 24(9):1753-1761

106. Shih SC, Sloper-Mould KE, Hicke L (2000) Monoubiquitin carries a novel internalization signal that is appended to activated receptors. EMBO J 19(2):187-198

107. Acconcia F, Sigismund S, Polo S (2009) Ubiquitin in trafficking: the network at work. Exp Cell Res 315(9):1610-1618

108. Pickart CM (2001) Mechanisms underlying ubiquitination. Annu Rev Biochem 70:503-533

109. Weissman AM (2001) Themes and variations on ubiquitylation. Nat Rev Mol Cell Biol 2(3):169-178

110. Bremm A, Komander D (2011) Emerging roles for Lys11linked polyubiquitin in cellular regulation. Trends Biochem Sci 36(7):355-363
111. Kulathu Y, Komander D (2012) Atypical ubiquitylation-the unexplored world of polyubiquitin beyond Lys48 and Lys63 linkages. Nat Rev Mol Cell Biol 13(8):508-523

112. Trempe JF (2011) Reading the ubiquitin postal code. Curr Opin Struct Biol 21(6):792-801

113. Nakasone MA et al (2013) Mixed-linkage ubiquitin chains send mixed messages. Structure 21(5):727-740

114. Sepp-Lorenzino L et al (1995) Herbimycin A induces the $20 \mathrm{~S}$ proteasome- and ubiquitin-dependent degradation of receptor tyrosine kinases. J Biol Chem 270(28):16580-16587

115. Carelli S et al (2006) Degradation of insulin-like growth factorI receptor occurs via ubiquitin-proteasome pathway in human lung cancer cells. J Cell Physiol 208(2):354-362

116. Girnita L, Girnita A, Larsson O (2003) Mdm2-dependent ubiquitination and degradation of the insulin-like growth factor 1 receptor. Proc Natl Acad Sci USA 100(14):8247-8252

117. Sehat B et al (2008) Identification of $\mathrm{c}-\mathrm{Cbl}$ as a new ligase for insulin-like growth factor-I receptor with distinct roles from $\mathrm{Mdm} 2$ in receptor ubiquitination and endocytosis. Cancer Res 68(14):5669-5677

118. Glogowska A et al (2012) Epidermal growth factor cytoplasmic domain affects ErbB protein degradation by the lysosomal and ubiquitin-proteasome pathway in human cancer cells. Neoplasia 14(5):396-409

119. Ancot $F$ et al (2012) Shedding-generated Met receptor fragments can be routed to either the proteasomal or the lysosomal degradation pathway. Traffic 13(9):1261-1272

120. Vecchione A et al (2003) The Grb10/Nedd4 complex regulates ligand-induced ubiquitination and stability of the insulin-like growth factor I receptor. Mol Cell Biol 23(9):3363-3372

121. Sehat B et al (2007) Role of ubiquitination in IGF-1 receptor signaling and degradation. PLoS ONE 2(4):e340

122. Dore S, Kar S, Quirion R (1997) Presence and differential internalization of two distinct insulin-like growth factor receptors in rat hippocampal neurons. Neuroscience 78(2):373-383

123. Segretin ME et al (2003) Insulin-like growth factor-1 receptor regulation in activated human $\mathrm{T}$ lymphocytes. Horm Res 59(6):276-280

124. Zheng $\mathrm{H}$ et al (2012) Selective recruitment of G-proteincoupled receptor kinases (GRKs) controls signaling of the insulin-like growth factor 1 receptor. Proc Natl Acad Sci USA 109(18):7055-7060

125. Ceresa BP, Schmid SL (2000) Regulation of signal transduction by endocytosis. Curr Opin Cell Biol 12(2):204-210

126. Johnson KF, Kornfeld S (1992) The cytoplasmic tail of the mannose 6-phosphate/insulin-like growth factor-II receptor has two signals for lysosomal enzyme sorting in the Golgi. J Cell Biol 119(2):249-257

127. Bremnes B et al (1994) An LI and ML motif in the cytoplasmic tail of the MHC-associated invariant chain mediate rapid internalization. J Cell Sci 107(Pt 7):2021-2032

128. Miura M, Baserga R (1997) The tyrosine residue at 1250 of the insulin-like growth factor I receptor is required for ligand-mediated internalization. Biochem Biophys Res Commun 239(1):182-185

129. Morrione A et al (1997) The role of mGrb10alpha in insulin-like growth factor I-mediated growth. J Biol Chem 272(42):26382-26387

130. Morrione A et al (1999) mGrb10 interacts with Nedd4. J Biol Chem 274(34):24094-24099

131. Monami G, Emiliozzi V, Morrione A (2008) Grb10/Nedd4mediated multiubiquitination of the insulin-like growth factor receptor regulates receptor internalization. J Cell Physiol 216(2):426-437

132. Werner $\mathrm{H}$ et al (1996) Wild-type and mutant p53 differentially regulate transcription of the insulin-like growth factor I receptor gene. Proc Natl Acad Sci USA 93(16):8318-8323 
133. Girnita L et al (2005) \{beta\}-Arrestin is crucial for ubiquitination and down-regulation of the insulin-like growth factor-1 receptor by acting as adaptor for the MDM2 E3 ligase. J Biol Chem 280(26):24412-24419

134. Girnita L et al (2007) Beta-arrestin and Mdm2 mediate IGF-1 receptor-stimulated ERK activation and cell cycle progression. $\mathrm{J}$ Biol Chem 282(15):11329-11338

135. Zwang Y, Yarden Y (2009) Systems biology of growth factorinduced receptor endocytosis. Traffic 10(4):349-363

136. Cao XR et al (2008) Nedd4 controls animal growth by regulating IGF-1 signaling. Sci Signal 1(38):ra5

137. Higashi $Y$ et al (2008) The ubiquitin ligase Nedd4 mediates oxidized low-density lipoprotein-induced downregulation of insulin-like growth factor-1 receptor. Am J Physiol Heart Circ Physiol 295(4):H1684-H1689

138. Romanelli RJ et al (2007) Insulin-like growth factor type-I receptor internalization and recycling mediate the sustained phosphorylation of Akt. J Biol Chem 282(31):22513-22524

139. Morcavallo A et al (2012) Insulin and insulin-like growth factor II differentially regulate endocytic sorting and stability of insulin receptor isoform A. J Biol Chem 287(14):11422-11436

140. Zheng $\mathrm{H}$ et al (2012) beta-Arrestin-biased agonism as the central mechanism of action for insulin-like growth factor 1 receptor-targeting antibodies in Ewing's sarcoma. Proc Natl Acad Sci USA 109(50):20620-20625

141. Mao Y et al (2011) Polyubiquitination of insulin-like growth factor I receptor (IGF-IR) activation loop promotes antibodyinduced receptor internalization and down-regulation. J Biol Chem 286(48):41852-41861

142. Broussas $M$ et al (2009) Molecular mechanisms involved in activity of h7C10, a humanized monoclonal antibody, to IGF-1 receptor. Int J Cancer 124(10):2281-2293

143. Vasilcanu R et al (2008) Insulin-like growth factor type-I receptor-dependent phosphorylation of extracellular signal-regulated kinase 1/2 but not Akt (protein kinase B) can be induced by picropodophyllin. Mol Pharmacol 73(3):930-939

144. Dalle $S$ et al (2001) Insulin and insulin-like growth factor I receptors utilize different G-protein signaling components. J Biol Chem 276(19):15688-15695

145. Rocchi $\mathrm{S}$ et al (1996) Interaction of SH2-containing-protein tyrosine phosphatase 2 with the insulin receptor and the insulin-like growth factor-I receptor: studies of the domains involved using the yeast two-hybrid system. Endocrinology 137(11):4944-4952

146. Maile LA, Clemmons DR (2002) The alphaVbeta3 integrin regulates insulin-like growth factor I (IGF-I) receptor phosphorylation by altering the rate of recruitment of the Src-homology 2-containing phosphotyrosine phosphatase-2 to the activated IGF-I receptor. Endocrinology 143(11):4259-4264

147. Kuemmerle JF (2006) Occupation of alphavbeta3-integrin by endogenous ligands modulates IGF-I receptor activation and proliferation of human intestinal smooth muscle. Am J Physiol Gastrointest Liver Physiol 290(6):G1194-G1202

148. Buckley DA et al (2002) Regulation of insulin-like growth factor type I (IGF-I) receptor kinase activity by protein tyrosine phosphatase 1B (PTP-1B) and enhanced IGF-I-mediated suppression of apoptosis and motility in PTP-1B-deficient fibroblasts. Mol Cell Biol 22(7):1998-2010

149. Blanquart $\mathrm{C}$ et al (2005) Monitoring the activation state of the insulin-like growth factor-1 receptor and its interaction with protein tyrosine phosphatase 1B using bioluminescence resonance energy transfer. Mol Pharmacol 68(3):885-894

150. Deng $\mathrm{H}$ et al (2010) Over-accumulation of nuclear IGF-1 receptor in tumor cells requires elevated expression of the receptor and the SUMO-conjugating enzyme Ubc9. Biochem Biophys Res Commun 404(2):667-671
151. Sehat B et al (2010) SUMOylation mediates the nuclear translocation and signaling of the IGF-1 receptor. Sci Signal 3(108):ra10

152. Sarfstein R et al (2012) Insulin-like growth factor-I receptor (IGF-IR) translocates to nucleus and autoregulates IGFIR gene expression in breast cancer cells. J Biol Chem 287(4):2766-2776

153. Asmane I et al (2012) Insulin-like growth factor type 1 receptor (IGF-1R) exclusive nuclear staining: a predictive biomarker for IGF-1R monoclonal antibody $(\mathrm{Ab})$ therapy in sarcomas. Eur $\mathbf{J}$ Cancer 48(16):3027-3035

154. Aleksic $\mathrm{T}$ et al (2010) Type 1 insulin-like growth factor receptor translocates to the nucleus of human tumor cells. Cancer Res 70(16):6412-6419

155. Sarfstein R, Werner H (2013) Minireview: nuclear insulin and insulin-like growth factor-1 receptors: a novel paradigm in signal transduction. Endocrinology 154:1672-1679

156. Pandini $G$ et al (2007) Functional responses and in vivo antitumour activity of h7C10: a humanised monoclonal antibody with neutralising activity against the insulin-like growth factor-1 (IGF-1) receptor and insulin/IGF-1 hybrid receptors. Eur J Cancer 43(8): 1318-1327

157. Belfiore A (2007) The role of insulin receptor isoforms and hybrid insulin/IGF-I receptors in human cancer. Curr Pharm Des 13(7):671-686

158. Belfiore A et al (1999) Insulin/IGF-I hybrid receptors play a major role in IGF-I signaling in thyroid cancer. Biochimie 81(4):403-407

159. Riedemann $\mathbf{J}$ et al (2007) The EGF receptor interacts with the type 1 IGF receptor and regulates its stability. Biochem Biophys Res Commun 355(3):707-714

160. Legate KR, Wickstrom SA, Fassler R (2009) Genetic and cell biological analysis of integrin outside-in signaling. Genes Dev 23(4):397-418

161. Ivaska J, Heino J (2010) Interplay between cell adhesion and growth factor receptors: from the plasma membrane to the endosomes. Cell Tissue Res 339(1):111-120

162. Maile LA et al (2002) Insulin-like growth factor I increases alpha Vbeta 3 affinity by increasing the amount of integrinassociated protein that is associated with non-raft domains of the cellular membrane. J Biol Chem 277(3):1800-1805

163. Manes S et al (1999) Concerted activity of tyrosine phosphatase SHP-2 and focal adhesion kinase in regulation of cell motility. Mol Cell Biol 19(4):3125-3135

164. Ling $\mathrm{Y}$ et al (2005) DOK1 mediates SHP-2 binding to the alphaVbeta3 integrin and thereby regulates insulin-like growth factor I signaling in cultured vascular smooth muscle cells. J Biol Chem 280(5):3151-3158

165. Jones JI et al (1996) Ligand occupancy of the alpha-V-beta3 integrin is necessary for smooth muscle cells to migrate in response to insulin-like growth factor. Proc Natl Acad Sci USA 93(6):2482-2487

166. Brooks PC et al (1997) Insulin-like growth factor receptor cooperates with integrin alpha $\mathrm{v}$ beta 5 to promote tumor cell dissemination in vivo. J Clin Invest 99(6):1390-1398

167. Ling Y, Maile LA, Clemmons DR (2003) Tyrosine phosphorylation of the beta3-subunit of the alphaVbeta3 integrin is required for embrane association of the tyrosine phosphatase SHP-2 and its further recruitment to the insulin-like growth factor I receptor. Mol Endocrinol 17(9):1824-1833

168. Maile LA, Badley-Clarke J, Clemmons DR (2003) The association between integrin-associated protein and SHPS-1 regulates insulin-like growth factor-I receptor signaling in vascular smooth muscle cells. Mol Biol Cell 14(9):3519-3528

169. Clemmons DR, Maile LA (2005) Interaction between insulinlike growth factor-I receptor and alphaVbeta3 integrin linked 
signaling pathways: cellular responses to changes in multiple signaling inputs. Mol Endocrinol 19(1):1-11

170. Clemmons DR, Maile LA (2003) Minireview: integral membrane proteins that function coordinately with the insulin-like growth factor I receptor to regulate intracellular signaling. Endocrinology 144(5):1664-1670

171. Edderkaoui $\mathrm{M}$ et al (2007) Insulin-like growth factor-I receptor mediates the prosurvival effect of fibronectin. J Biol Chem 282(37):26646-26655

172. Shakibaei M et al (1999) Signal transduction by betal integrin receptors in human chondrocytes in vitro: collaboration with the insulin-like growth factor-I receptor. Biochem J 342(Pt 3):615-623

173. Kiely PA et al (2006) Insulin-like growth factor I controls a mutually exclusive association of RACK1 with protein phosphatase $2 \mathrm{~A}$ and beta1 integrin to promote cell migration. Mol Cell Biol 26(11):4041-4051

174. O'Donovan HC, Kiely PA, O'Connor R (2007) Effects of RACK1 on cell migration and IGF-I signaling in cardiomyocytes are not dependent on an association with the IGF-IR. Cell Signal 19(12):2588-2595

175. Saegusa J et al (2009) The direct binding of insulin-like growth factor-1 (IGF-1) to integrin alphavbeta3 is involved in IGF-1 signaling. J Biol Chem 284(36):24106-24114

176. Fujita $\mathrm{M}$ et al (2013) An integrin-binding-defective mutant of insulin-like growth factor-1 (R36E/R37E IGF1) acts as a dominant-negative antagonist of IGF1R and suppresses tumorigenesis, while the mutant still binds to IGF1R. J Biol Chem

177. Fujita $\mathrm{M}$ et al (2012) Cross-talk between integrin alpha6beta4 and insulin-like growth factor-1 receptor (IGF1R) through direct alpha6beta4 binding to IGF1 and subsequent alpha6beta4-IGF1-IGF1R ternary complex formation in anchorageindependent conditions. J Biol Chem 287(15):12491-12500

178. Fujita $\mathrm{M}$ et al (2013) An integrin binding-defective mutant of insulin-like growth factor-1 (R36E/R37E IGF1) acts as a dominant-negative antagonist of the IGF1 receptor (IGF1R) and suppresses tumorigenesis but still binds to IGF1R. J Biol Chem 288(27):19593-19603

179. Waters C, Pyne S, Pyne NJ (2004) The role of G-protein coupled receptors and associated proteins in receptor tyrosine kinase signal transduction. Semin Cell Dev Biol 15(3):309-323

180. Daub H et al (1997) Signal characteristics of G-protein-transactivated EGF receptor. EMBO J 16(23):7032-7044

181. Pyne NJ, Pyne S (2011) Receptor tyrosine kinase-G-proteincoupled receptor signaling platforms: out of the shadow? Trends Pharmacol Sci 32(8):443-450

182. Rao GN, Delafontaine P, Runge MS (1995) Thrombin stimulates phosphorylation of insulin-like growth factor-1 receptor, insulin receptor substrate-1, and phospholipase C-gamma 1 in rat aortic smooth muscle cells. J Biol Chem 270(46):27871-27875

183. Zhao D et al (2011) Insulin-like growth factor-1 receptor transactivation modulates the inflammatory and proliferative responses of neurotensin in human colonic epithelial cells. J Biol Chem 286(8):6092-6099

184. Oligny-Longpre $\mathrm{G}$ et al (2012) Engagement of beta-arrestin by transactivated insulin-like growth factor receptor is needed for V2 vasopressin receptor-stimulated ERK1/2 activation. Proc Natl Acad Sci USA 109(17):E1028-E1037

185. Luttrell LM et al (1995) G beta gamma subunits mediate mitogen-activated protein kinase activation by the tyrosine kinase insulin-like growth factor 1 receptor. J Biol Chem 270(28):16495-16498

186. Luttrell L et al (1990) A pertussis toxin-sensitive G-protein mediates some aspects of insulin action in $\mathrm{BC} 3 \mathrm{H}-1$ murine myocytes. J Biol Chem 265(28):16873-16879
187. Delcourt N, Bockaert J, Marin P (2007) GPCR-jacking: from a new route in RTK signaling to a new concept in GPCR activation. Trends Pharmacol Sci 28(12):602-607

188. Heyworth CM et al (1986) The action of islet activating-protein (pertussis toxin) on insulin's ability to inhibit adenylate cyclase and activate cyclic AMP phosphodiesterases in hepatocytes. Biochem J 235(1):145-149

189. Rothenberg PL, Kahn CR (1988) Insulin inhibits pertussis toxin-catalyzed ADP-ribosylation of G-proteins. Evidence for a novel interaction between insulin receptors and G-proteins. J Biol Chem 263(30):15546-15552

190. Hallak $\mathrm{H}$ et al (2000) Association of heterotrimeric G(i) with the insulin-like growth factor-I receptor. Release of G(betagamma) subunits upon receptor activation. J Biol Chem 275(4):2255-2258

191. Lin FT, Daaka Y, Lefkowitz RJ (1998) beta-Arrestins regulate mitogenic signaling and clathrin-mediated endocytosis of the insulin-like growth factor I receptor. J Biol Chem 273(48):31640-31643

192. Shenoy SK et al (2006) beta-Arrestin-dependent, G-proteinindependent ERK1/2 activation by the beta2 adrenergic receptor. J Biol Chem 281(2):1261-1273

193. Lefkowitz RJ, Shenoy SK (2005) Transduction of receptor signals by beta-arrestins. Science 308(5721):512-517

194. Lefkowitz RJ (2004) Historical review: a brief history and personal retrospective of seven-transmembrane receptors. Trends Pharmacol Sci 25(8):413-422

195. Shenoy SK, Lefkowitz RJ (2003) Multifaceted roles of betaarrestins in the regulation of seven-membrane-spanning receptor trafficking and signaling. Biochem J 375(Pt 3):503-515

196. DeWire SM et al (2007) Beta-arrestins and cell signaling. Annu Rev Physiol 69:483-510

197. Reiter E, Lefkowitz RJ (2006) GRKs and beta-arrestins: roles in receptor silencing, trafficking and signaling. Trends Endocrinol Metab 17(4):159-165

198. Gao J, Li J, Ma L (2005) Regulation of EGF-induced ERK/MAPK activation and EGFR internalization by G-proteincoupled receptor kinase 2. Acta Biochim Biophys Sin (Shanghai) $37(8): 525-531$

199. Freedman NJ et al (2002) Phosphorylation of the plateletderived growth factor receptor-beta and epidermal growth factor receptor by G-protein-coupled receptor kinase-2. Mechanisms for selectivity of desensitization. J Biol Chem 277(50):48261-48269

200. Usui I et al (2004) GRK2 is an endogenous protein inhibitor of the insulin signaling pathway for glucose transport stimulation. EMBO J 23(14):2821-2829

201. Pitcher JA, Freedman NJ, Lefkowitz RJ (1998) G-protein-coupled receptor kinases. Annu Rev Biochem 67:653-692

202. Perrault $\mathrm{R}$ et al (2011) Tyrosine kinase-independent activation of extracellular-regulated kinase (ERK) $1 / 2$ by the insulin-like growth factor-1 receptor. Cell Signal 23(4):739-746

203. Frattali AL, Treadway JL, Pessin JE (1992) Insulin/IGF-1 hybrid receptors: implications for the dominant-negative phenotype in syndromes of insulin resistance. J Cell Biochem 48(1):43-50

204. Povsic TJ, Kohout TA, Lefkowitz RJ (2003) Beta-arrestin1 mediates insulin-like growth factor 1 (IGF-1) activation of phosphatidylinositol 3-kinase (PI3K) and anti-apoptosis. J Biol Chem 278(51):51334-51339

205. Arteaga CL (1992) Interference of the IGF system as a strategy to inhibit breast cancer growth. Breast Cancer Res Treat 22(1):101-106

206. Kalebic T, Tsokos M, Helman LJ (1994) In vivo treatment with antibody against IGF-1 receptor suppresses growth of human rhabdomyosarcoma and down-regulates p34cdc2. Cancer Res 54(21):5531-5534 
207. Trojan J et al (1992) Loss of tumorigenicity of rat glioblastoma directed by episome-based antisense cDNA transcription of insulin-like growth factor I. Proc Natl Acad Sci USA 89(11):4874-4878

208. Resnicoff M et al (1994) Rat glioblastoma cells expressing an antisense RNA to the insulin-like growth factor-1 (IGF-1) receptor are nontumorigenic and induce regression of wild-type tumors. Cancer Res 54(8):2218-2222

209. Resnicoff M et al (1994) Growth inhibition of human melanoma cells in nude mice by antisense strategies to the type 1 insulinlike growth factor receptor. Cancer Res 54(18):4848-4850

210. Shapiro DN et al (1994) Antisense-mediated reduction in insulin-like growth factor-I receptor expression suppresses the malignant phenotype of a human alveolar rhabdomyosarcoma. J Clin Invest 94(3): 1235-1242

211. Reiss K et al (1998) Inhibition of tumor growth by a dominant negative mutant of the insulin-like growth factor I receptor with a bystander effect. Clin Cancer Res 4(11):2647-2655

212. Long L et al (1995) Loss of the metastatic phenotype in murine carcinoma cells expressing an antisense RNA to the insulin-like growth factor receptor. Cancer Res 55(5):1006-1009

213. Dunn SE et al (1998) A dominant negative mutant of the insulin-like growth factor-I receptor inhibits the adhesion, invasion, and metastasis of breast cancer. Cancer Res 58(15):3353-3361

214. Kanter-Lewensohn L et al (2000) Tamoxifen-induced cell death in malignant melanoma cells: possible involvement of the insulin-like growth factor-1 (IGF-1) pathway. Mol Cell Endocrinol 165(1-2):131-137

215. Scartozzi M et al (2011) State of the art and future perspectives for the use of insulin-like growth factor receptor 1 (IGF1R) targeted treatment strategies in solid tumors. Discov Med 11(57):144-153

216. Baserga R (2000) The contradictions of the insulin-like growth factor 1 receptor. Oncogene 19(49):5574-5581

217. Kanter-Lewensohn L et al (2000) Expression of insulin-like growth factor-1 receptor (IGF-1R) and p27Kip1 in melanocytic tumors: a potential regulatory role of IGF-1 pathway in distribution of p27Kip1 between different cyclins. Growth Factors 17(3):193-202

218. Navab R et al (2001) Inhibition of endosomal insulin-like growth factor-I processing by cysteine proteinase inhibitors blocks receptor-mediated functions. J Biol Chem 276(17):13644-13649

219. Ren SG et al (1992) Somatostatin analog induces insulin-like growth factor binding-protein-1 (IGFBP-1) expression in human hepatoma cells. Endocrinology 131(5):2479-2481

220. Pietrzkowski $Z$ et al (1993) Inhibition of growth of prostatic cancer cell lines by peptide analogues of insulin-like growth factor 1. Cancer Res 53(5):1102-1106

221. Rohlik QT et al (1987) An antibody to the receptor for insulinlike growth factor I inhibits the growth of MCF-7 cells in tissue culture. Biochem Biophys Res Commun 149(1):276-281

222. Rosenzweig SA, Atreya HS (2010) Defining the pathway to insulin-like growth factor system targeting in cancer. Biochem Pharmacol 80(8):1115-1124

223. Firth SM, Baxter RC (2002) Cellular actions of the insulin-like growth factor binding-proteins. Endocr Rev 23(6):824-854

224. Dransfield DT et al (2010) A human monoclonal antibody against insulin-like growth factor-II blocks the growth of human hepatocellular carcinoma cell lines in vitro and in vivo. Mol Cancer Ther 9(6):1809-1819

225. Gao J et al (2011) Dual IGF-I/II-neutralizing antibody MEDI573 potently inhibits IGF signaling and tumor growth. Cancer Res 71(3):1029-1040

226. Zhao Q et al (2011) Human monoclonal antibody fragments binding to insulin-like growth factors I and II with picomolar affinity. Mol Cancer Ther 10(9):1677-1685
227. Feng $Y$ et al (2006) Novel human monoclonal antibodies to insulin-like growth factor (IGF)-II that potently inhibit the IGF receptor type I signal transduction function. Mol Cancer Ther 5(1):114-120

228. Olmos D et al (2011) Targeting the insulin-like growth factor 1 receptor in Ewing's sarcoma: reality and expectations. Sarcoma 2011(402508):402508

229. Olmos D et al (2009) Safety, pharmacokinetics, and preliminary activity of the anti-IGF-1R antibody figitumumab (CP-751,871) in patients with sarcoma and Ewing's sarcoma: a phase 1 expansion cohort study. Lancet Oncol 11(2):129-135

230. Juergens $\mathrm{H}$ et al (2011) Preliminary efficacy of the anti-insulin-like growth factor type 1 receptor antibody figitumumab in patients with refractory Ewing sarcoma. J Clin Oncol 29(34):4534-4540

231. Gualberto A et al (2010) Molecular analysis of non-small cell lung cancer identifies subsets with different sensitivity to insulin-like growth factor I receptor inhibition. Clin Cancer Res 16(18):4654-4665

232. Corral J et al (2011) Pathologic complete responses after chemotherapy plus figitumumab in stage IV non-small-cell lung cancer. J Clin Oncol 29(7):e163-e165

233. Burgaud JL, Resnicoff M, Baserga R (1995) Mutant IGF-I receptors as dominant negatives for growth and transformation. Biochem Biophys Res Commun 214(2):475-481

234. Li S et al (1994) Mitogenicity and transforming activity of the insulin-like growth factor-I receptor with mutations in the tyrosine kinase domain. J Biol Chem 269(51):32558-32564

235. Kalebic $\mathrm{T}$ et al (1998) Expression of a kinase-deficient IGFI-R suppresses tumorigenicity of rhabdomyosarcoma cells constitutively expressing a wild type IGF-I-R. Int J Cancer 76(2):223-227

236. Scotlandi K et al (2002) Expression of an IGF-I receptor dominant negative mutant induces apoptosis, inhibits tumorigenesis and enhances chemosensitivity in Ewing's sarcoma cells. Int J Cancer 101(1):11-16

237. Brodt P, Samani A, Navab R (2000) Inhibition of the type I insulin-like growth factor receptor expression and signaling: novel strategies for antimetastatic therapy. Biochem Pharmacol 60(8):1101-1107

238. Buck E, Mulvihill M (2011) Small molecule inhibitors of the IGF-1R/IR axis for the treatment of cancer. Expert Opin Investig Drugs 20(5):605-621

239. Jin $\mathrm{M}$ et al (2012) Small-molecule ATP-competitive dual IGF-1R and insulin receptor inhibitors: structural insights, chemical diversity and molecular evolution. Future Med Chem 4(3):315-328

240. Buck E et al (2010) Compensatory insulin receptor (IR) activation on inhibition of insulin-like growth factor-1 receptor (IGF1R): rationale for cotargeting IGF-1R and IR in cancer. Mol Cancer Ther 9(10):2652-2664

241. Ulanet DB et al (2010) Insulin receptor functionally enhances multistage tumor progression and conveys intrinsic resistance to IGF-1R targeted therapy. Proc Natl Acad Sci USA 107(24):10791-10798

242. Mitsiades CS et al (2004) Inhibition of the insulin-like growth factor receptor-1 tyrosine kinase activity as a therapeutic strategy for multiple myeloma, other hematologic malignancies, and solid tumors. Cancer Cell 5(3):221-230

243. Scotlandi K et al (2005) Antitumor activity of the insulin-like growth factor-I receptor kinase inhibitor NVP-AEW541 in musculoskeletal tumors. Cancer Res 65(9):3868-3876

244. Mulvihill MJ et al (2009) Discovery of OSI-906: a selective and orally efficacious dual inhibitor of the IGF-1 receptor and insulin receptor. Future Med Chem 1(6):1153-1171

245. Vasilcanu D et al (2004) The cyclolignan PPP induces activation loop-specific inhibition of tyrosine phosphorylation of 
the insulin-like growth factor-1 receptor. Link to the phosphatidyl inositol-3 kinase/Akt apoptotic pathway. Oncogene 23(47):7854-7862

246. Ahlen $\mathrm{J}$ et al (2005) Insulin-like growth factor type 1 receptor expression correlates to good prognosis in highly malignant soft tissue sarcoma. Clin Cancer Res 11(1):206-216

247. Economou MA et al (2005) Receptors for the liver synthesized growth factors IGF-1 and HGF/SF in uveal melanoma: intercorrelation and prognostic implications. Invest Ophthalmol Vis Sci 46(12):4372-4375

248. Economou MA et al (2008) Oral picropodophyllin (PPP) is well tolerated in vivo and inhibits IGF-1R expression and growth of uveal melanoma. Invest Ophthalmol Vis Sci 49(6):2337-2342

249. Menu $E$ et al (2006) Inhibiting the IGF-1 receptor tyrosine kinase with the cyclolignan PPP: an in vitro and in vivo study in the 5T33MM mouse model. Blood 107(2):655-660

250. Natalishvili $N$ et al (2009) Aberrant intracellular IGF-1R betasubunit makes receptor knockout cells (IGF1R-/-) susceptible to oncogenic transformation. Exp Cell Res 315(8):1458-1467

251. Razuvaev A et al (2007) The cyclolignan picropodophyllin attenuates intimal hyperplasia after rat carotid balloon injury by blocking insulin-like growth factor-1 receptor signaling. J Vasc Surg 46(1):108-115

252. Stromberg T et al (2006) IGF-1 receptor tyrosine kinase inhibition by the cyclolignan PPP induces G2/M-phase accumulation and apoptosis in multiple myeloma cells. Blood 107(2):669-678

253. Vitale $M$ et al (2008) New picropodophyllin analogs via palladium-catalyzed allylic alkylation-Hiyama cross-coupling sequences. J Org Chem 73(15):5795-5805

254. Conti L et al (2007) In the absence of IGF-1 signaling, IFNgamma suppresses human malignant T-cell growth. Blood 109(6):2496-2504

255. Jernberg-Wiklund H, Nilsson K (2007) Control of apoptosis in human multiple myeloma by insulin-like growth factor I (IGFI). Adv Cancer Res 97:139-165

256. Menu E et al (2007) Targeting the IGF-1R using picropodophyllin in the therapeutical 5T2MM mouse model of multiple myeloma: beneficial effects on tumor growth, angiogenesis, bone disease and survival. Int J Cancer 121(8):1857-1861

257. Nussbaum T et al (2008) Autocrine insulin-like growth factorII stimulation of tumor cell migration is a progression step in human hepatocarcinogenesis. Hepatology 48(1):146-156

258. Klinakis A et al (2009) Igf1r as a therapeutic target in a mouse model of basal-like breast cancer. Proc Natl Acad Sci USA 106(7):2359-2364

259. Hashemi $\mathbf{J}$ et al (2011) Molecular characterization of acquired tolerance of tumor cells to picropodophyllin (PPP). PLoS ONE 6(3):e14757

260. Rosengren L et al (2006) IGF-1R tyrosine kinase expression and dependency in clones of IGF-1R knockout cells (R-). Biochem Biophys Res Commun 347(4):1059-1066

261. Ekman S et al (2011) Clinical phase I study with an insulinlike growth factor-1 receptor inhibitor: experiences in patients with squamous non-small cell lung carcinoma. Acta Oncol 50(3):441-447

262. Dong JY et al (2011) A stable IgG-like bispecific antibody targeting the epidermal growth factor receptor and the type I insulin-like growth factor receptor demonstrates superior anti-tumor activity. MAbs 3(3):273-288

263. Rowinsky EK et al (2007) IMC-A12, a human IgG, monoclonal antibody to the insulin-like growth factor I receptor. Clin Cancer Res 13(18):5549S-5555S

264. Runnels HA et al (2010) Human monoclonal antibodies to the insulin-like growth factor 1 receptor inhibit receptor activation and tumor growth in preclinical studies. Adv Ther 27(7):458-475
265. Wang Y et al (2005) Inhibition of insulin-like growth factor-I receptor (IGF-IR) signaling and tumor cell growth by a fully human neutralizing anti-IGF-IR antibody. Mol Cancer Ther 4(8):1214-1221

266. Garofalo $\mathrm{C}$ et al (2012) Identification of common and distinctive mechanisms of resistance to different anti-IGF-IR agents in Ewing's sarcoma. Mol Endocrinol 26(9):1603-1616

267. Takahashi K, Yonezawa K, Nishimoto I (1995) Insulin-like growth factor I receptor activated by a transmembrane mutation. J Biol Chem 270(32):19041-19045

268. Craparo A, O'Neill TJ, Gustafson TA (1995) Non-SH2 domains within insulin receptor substrate-1 and SHC mediate their phosphotyrosine-dependent interaction with the NPEY motif of the insulin-like growth factor I receptor. J Biol Chem 270(26):15639-15643

269. Tartare-Deckert $S$ et al (1995) Evidence for a differential interaction of SHC and the insulin receptor substrate-1 (IRS-1) with the insulin-like growth factor-I (IGF-I) receptor in the yeast two-hybrid system. J Biol Chem 270(40):23456-23460

270. He W et al (1996) Interaction of insulin receptor substrate-2 (IRS-2) with the insulin and insulin-like growth factor I receptors. Evidence for two distinct phosphotyrosinedependent interaction domains within IRS-2. J Biol Chem 271(20):11641-11645

271. Xu P, Jacobs AR, Taylor SI (1999) Interaction of insulin receptor substrate 3 with insulin receptor, insulin receptor-related receptor, insulin-like growth factor-1 receptor, and downstream signaling-proteins. J Biol Chem 274(21):15262-15270

272. Dey BR et al (1996) Evidence for the direct interaction of the insulin-like growth factor I receptor with IRS-1, Shc, and Grb10. Mol Endocrinol 10(6):631-641

273. Beitner-Johnson D et al (1995) Regulation of insulin-like growth factor I receptor gene expression by Sp1: physical and functional interactions of Sp1 at GC boxes and at a CT element. Mol Endocrinol 9(9):1147-1156

274. Koval AP et al (1998) Interaction in vitro of the product of the c-Crk-II proto-oncogene with the insulin-like growth factor I receptor. Biochem J 330(Pt 2):923-932

275. Miura M, Li S, Baserga R (1995) Effect of a mutation at tyrosine 950 of the insulin-like growth factor I receptor on the growth and transformation of cells. Cancer Res 55(3):663-667

276. Jiang $\mathrm{Y}$ et al (1996) Effect of tyrosine mutations on the kinase activity and transforming potential of an oncogenic human insulin-like growth factor I receptor. J Biol Chem 271(1):160-167

277. Esposito DL et al (1997) Tyrosine residues in the C-terminal domain of the insulin-like growth factor-I receptor mediate mitogenic and tumorigenic signals. Endocrinology 138(7):2979-2988

278. Yamasaki $\mathrm{H}$ et al (1992) Human insulin-like growth factor I receptor 950tyrosine is required for somatotroph growth factor signal transduction. J Biol Chem 267(29):20953-20958

279. Kato $\mathrm{H}$ et al (1993) Role of tyrosine kinase activity in signal transduction by the insulin-like growth factor-I (IGF-I) receptor. Characterization of kinase-deficient IGF-I receptors and the action of an IGF-I-mimetic antibody (alpha IR-3). J Biol Chem 268(4):2655-2661

280. Kelly GM et al (2012) Serine phosphorylation of the insulin-like growth factor I (IGF-1) receptor C-terminal tail restrains kinase activity and cell growth. J Biol Chem 287(33):28180-28194

281. Kruis $\mathrm{T}$ et al (2010) Heterozygous mutation within a kinaseconserved motif of the insulin-like growth factor I receptor causes intrauterine and postnatal growth retardation. J Clin Endocrinol Metab 95(3):1137-1142

282. Stannard B et al (1995) Single tyrosine substitution in the insulin-like growth factor I receptor inhibits ligand-induced receptor autophosphorylation and internalization, but not mitogenesis. Endocrinology 136(11):4918-4924 
283. Hernandez-Sanchez C et al (1995) The role of the tyrosine kinase domain of the insulin-like growth factor-I receptor in intracellular signaling, cellular proliferation, and tumorigenesis. J Biol Chem 270(49):29176-29181

284. Blakesley VA et al (1995) Mutation of a conserved amino acid residue (tryptophan 1173) in the tyrosine kinase domain of the IGF-I receptor abolishes autophosphorylation but does not eliminate biologic function. J Biol Chem 270(6):2764-2769

285. Brodt $\mathrm{P}$ et al (2001) Cooperative regulation of the invasive and metastatic phenotypes by different domains of the type I insulin-like growth factor receptor beta subunit. J Biol Chem 276(36):33608-33615

286. Miura M et al (1995) Different effects on mitogenesis and transformation of a mutation at tyrosine 1251 of the insulin-like growth factor I receptor. J Biol Chem 270(38):22639-22644

287. Craparo A, Freund R, Gustafson TA (1997) 14-3-3 (epsilon) interacts with the insulin-like growth factor I receptor and insulin receptor substrate $\mathrm{I}$ in a phosphoserine-dependent manner. J Biol Chem 272(17):11663-11669

288. Furlanetto RW et al (1997) 14-3-3 proteins interact with the insulin-like growth factor receptor but not the insulin receptor. Biochem J 327(Pt 3):765-771

289. Peruzzi $\mathrm{F}$ et al (2001) Anti-apoptotic signaling of the insulinlike growth factor-I receptor through mitochondrial translocation of c-Raf and Nedd4. J Biol Chem 276(28):25990-25996

290. Li S, Resnicoff M, Baserga R (1996) Effect of mutations at serines 1280-1283 on the mitogenic and transforming activities of the insulin-like growth factor I receptor. J Biol Chem 271(21):12254-12260

291. Dews M et al (2000) Domains of the insulin-like growth factor I receptor required for the activation of extracellular signalregulated kinases. Endocrinology 141(4):1289-1300

292. Hongo A et al (1996) Mutational analysis of the mitogenic and transforming activities of the insulin-like growth factor I receptor. Oncogene 12(6):1231-1238

293. Lamothe B et al (1995) Interaction of $\mathrm{p} 85$ subunit of PI 3-kinase with insulin and IGF-1 receptors analysed by using the twohybrid system. FEBS Lett 373(1):51-55

294. O'Connor R (2003) Regulation of IGF-I receptor signaling in tumor cells. Horm Metab Res 35(11-12):771-777

295. Fernandez CA et al (2010) The anti-angiogenic peptide, loop 6 , binds insulin-like growth factor-1 receptor. J Biol Chem 285(53):41886-41895

296. Dey BR, Furlanetto RW, Nissley P (2000) Suppressor of cytokine signaling (SOCS)-3 protein interacts with the insulinlike growth factor-I receptor. Biochem Biophys Res Commun 278(1):38-43

297. Dey BR, Furlanetto RW, Nissley SP (1998) Cloning of human p55 gamma, a regulatory subunit of phosphatidylinositol 3-kinase, by a yeast two-hybrid library screen with the insulinlike growth factor-I receptor. Gene 209(1-2):175-183

298. Gual $\mathrm{P}$ et al (1998) Interaction of Janus kinases JAK-1 and JAK-2 with the insulin receptor and the insulin-like growth factor-1 receptor. Endocrinology 139(3):884-893 